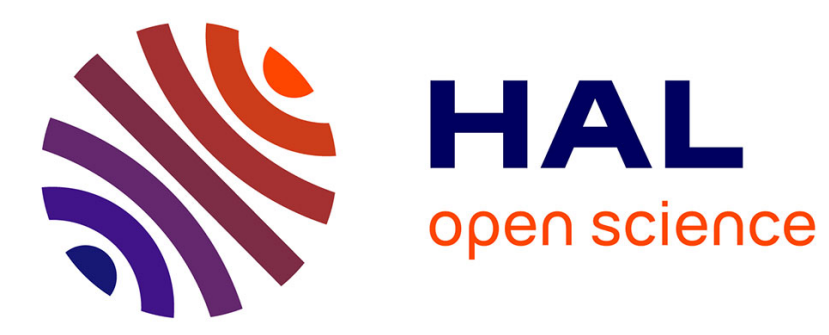

\title{
Synthesis of novel diosgenyl saponin analogs and evaluation effects of rhamnose moeity on their cytotoxic activity
}

Xin Meng, Yiwu Pan, Tao Liu, Chen Luo, Shuli Man, Yongmin Zhang, Yan Zhang

\section{To cite this version:}

Xin Meng, Yiwu Pan, Tao Liu, Chen Luo, Shuli Man, et al.. Synthesis of novel diosgenyl saponin analogs and evaluation effects of rhamnose moeity on their cytotoxic activity. Carbohydrate Research, 2021, 506, pp.108359. 10.1016/j.carres.2021.108359 . hal-03360261

\section{HAL Id: hal-03360261 \\ https: / hal.sorbonne-universite.fr/hal-03360261}

Submitted on 30 Sep 2021

HAL is a multi-disciplinary open access archive for the deposit and dissemination of scientific research documents, whether they are published or not. The documents may come from teaching and research institutions in France or abroad, or from public or private research centers.
L'archive ouverte pluridisciplinaire HAL, est destinée au dépôt et à la diffusion de documents scientifiques de niveau recherche, publiés ou non, émanant des établissements d'enseignement et de recherche français ou étrangers, des laboratoires publics ou privés. 


\title{
Carbohydrate Research
}

\section{Synthesis of novel diosgenyl saponin analogs and evaluation effects of rhamnose moeity on their cytotoxic activity}

\author{
Xin Meng a , Yiwu Pan ${ }^{\text {a }}$, Tao Liu ${ }^{a}$, Chen Luo ${ }^{a}$, Shuli Man ${ }^{\text {a }}$, Yongmin Zhang a,c , Yan Zhang ${ }^{\text {b, * }}$ \\ ${ }^{a}$ Key Laboratory of Industrial Microbiology, Ministry of Education, College of Biotechnology, Tianjin University of Science and Technology, China \\ International Science and Technology Cooperation Base of Food Nutrition/Safety and Medicinal Chemistry, Tianjin 300457, PR China \\ ${ }^{b}$ Department of Pharmacy, Qilu Hospital of Shandong University, Jinan 250012, Shandong Province, PR China \\ c Sorbonne Université, Institut Parisien de Chimie Moléculaire, UMR CNRS 8232, 4 place Jussieu, 75005, Paris, France
}

\section{ARTICLE INFO}

Article history:

Received

Revised

Accepted

Available online

\section{Keywords:}

Diosgenyl saponins

Hepatocellular carcinoma

Synthesis

Glycosylation

Analogs

\section{ABSTRACT}

\section{Introduction}

Hepatocellular cancer (HCC), the most common liver cancer, is rising at an alarming rate worldwide and it leads to advanced liver diseases. Many reports suggested that diosgenin (DSG) and diosgenyl saponins imparted anti-cancer effects on HCC cells [14]. However, poor pharmacokinetic profile, low aqueous solubility, and instability in different physiological conditions limit the usage of DSG for clinical applications. A modification at the C3 position of DSG changes its physiochemical characteristics drastically and improves the adsorption, distribution, metabolism, elimination, and biological activities of DSG [5-7].

The typical structure of the glycan in diosgenyl saponins is one with a $\beta$-D-glucopyranoside as the first sugar attached to diosgenin, which in turn has an $\alpha$-L-rhamnopyranose substituted at 2-OH and another sugar chain at $4-\mathrm{OH}$. The structure diversity of the steroidal saponins mainly lay on the carbohydrate moieties present on it, which effected their activities significantly [8]. In the last two decades, an increasing number of natural and nonnatural steroidal saponins have been synthesized and evaluated for their anticancer activity [9]. Many studies have disclosed that DSG glycosides were better apoptosis-inducers than DSG and the structure of the sugar residues, especially for the 2-OH and 4-OH branches elongated from the glucose and rhamnose residues play crucial roles in triggering cell death by

\footnotetext{
* Corresponding author. E-mail: zhangyansdu@email.sdu.edu.cn (Y. Zhang)
}

apoptosis [10-14]. However, only the activity of diosgenyl saponins containing shorter glycans than trisaccharide have been relatively extensive studied $[15,16]$. While, the structure-activity relations of diosgenyl saponins containing longer 2, 4-branched oligosaccharides moiety have never been explored and complex diosgenyl saponins with longer carbohydrate residues were rarely synthesized [17].

Our research group has reported the activity of some steroidal glycosides, in which, their structure-activity relationships and roles as apoptosis or necrosis inducers have been established [3, 18-21]. Specially, these bioactive saponins are comprised of a 2,4-branched oligosaccharide moiety. Because of their biological funtions and also their unique 2,4-dibranched chain structures, the efficient synthesis of these diosgenyl glycosides deserves extensive exploration. As part of the ongoing efforts in discovering new bioactive compounds, the present work is concerned with the structure-activity relationship upon the sugar chains of diosgenyl glycosides. A series of diosgenyl glycosides (Fig. 1), 1 (diosgenyl O- $\alpha$-L-rhamnopyranosyl-( $1 \rightarrow 2)-\beta-D-$ glucopyranoside); 2 Dioscin (diosgenyl 2,4-di- $O-\alpha-\mathrm{L}-$ rhamnopyranosyl- $\alpha$-D-glucopyranoside), 3 polyphyllin D (diosgenyl $\alpha$-L-rhamno-pyranosyl-( $1 \rightarrow 2)$-[ $\alpha$-L-arabinofuranosyl$(1 \rightarrow 4)]-\beta$-D-glucopyranoside), $4 \quad$ (diosgenyl $\alpha$-Lrhamnopyranosyl- $(1 \rightarrow 2)$-[ $\alpha$-L-rhamnopyranosyl- $(1 \rightarrow 4)-\alpha$-Lrhamnopyranosyl-( $1 \rightarrow 4)]-\beta$-D-glucopyranoside), 5 (diosgenyl $\alpha$ L-rhamnopyranosyl-( $1 \rightarrow 2)$-[ $\alpha$-L-rhamnopyranosyl-( $1 \rightarrow 4)-\alpha$-Lrhamnopyranosyl-( $(1 \rightarrow 4)-\alpha$-L-rhamnopyranosyl- $(1 \rightarrow 4)]-\beta-D$ 


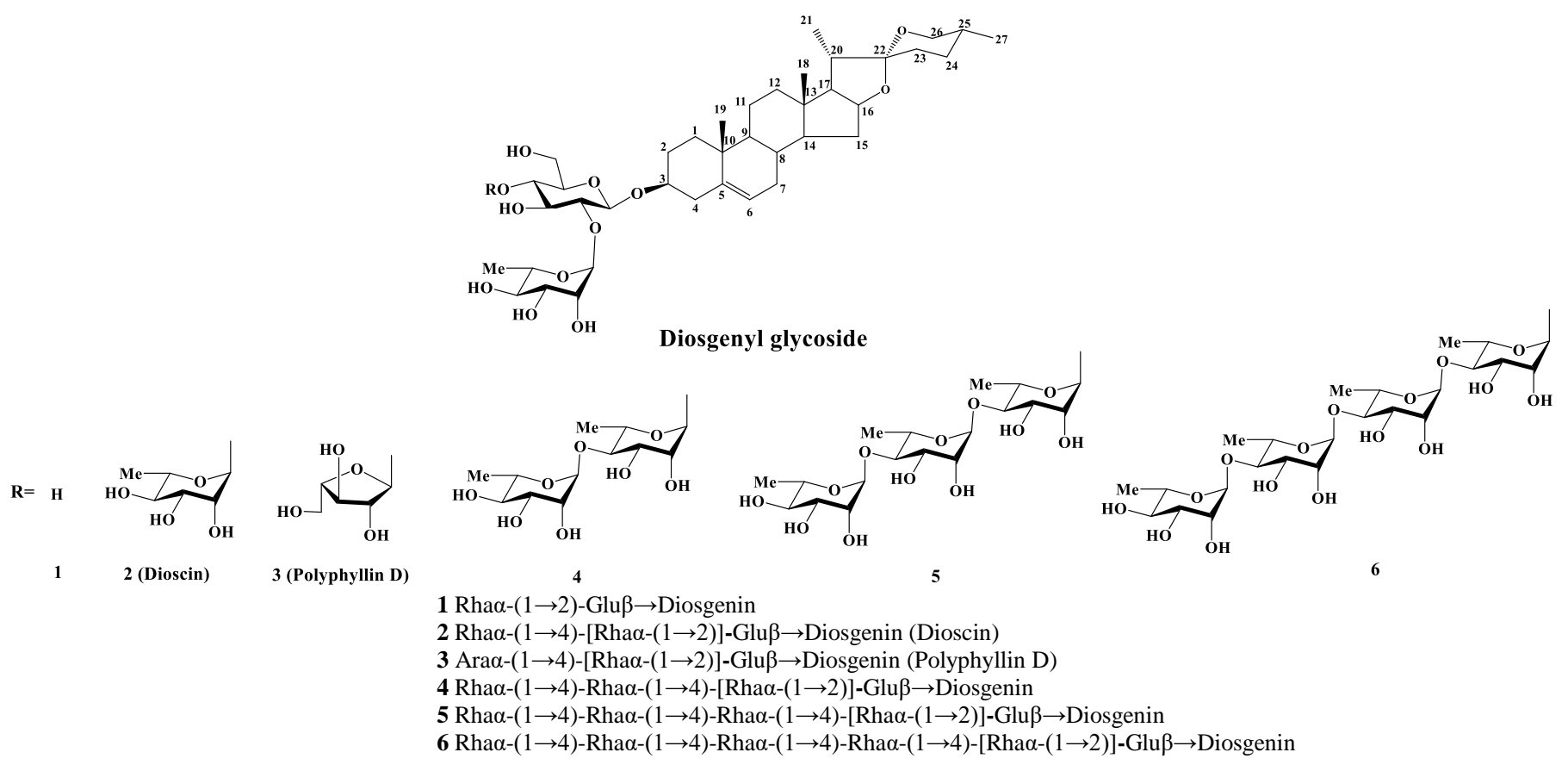

Fig. 1. Diosgenyl saponins and their analogs.
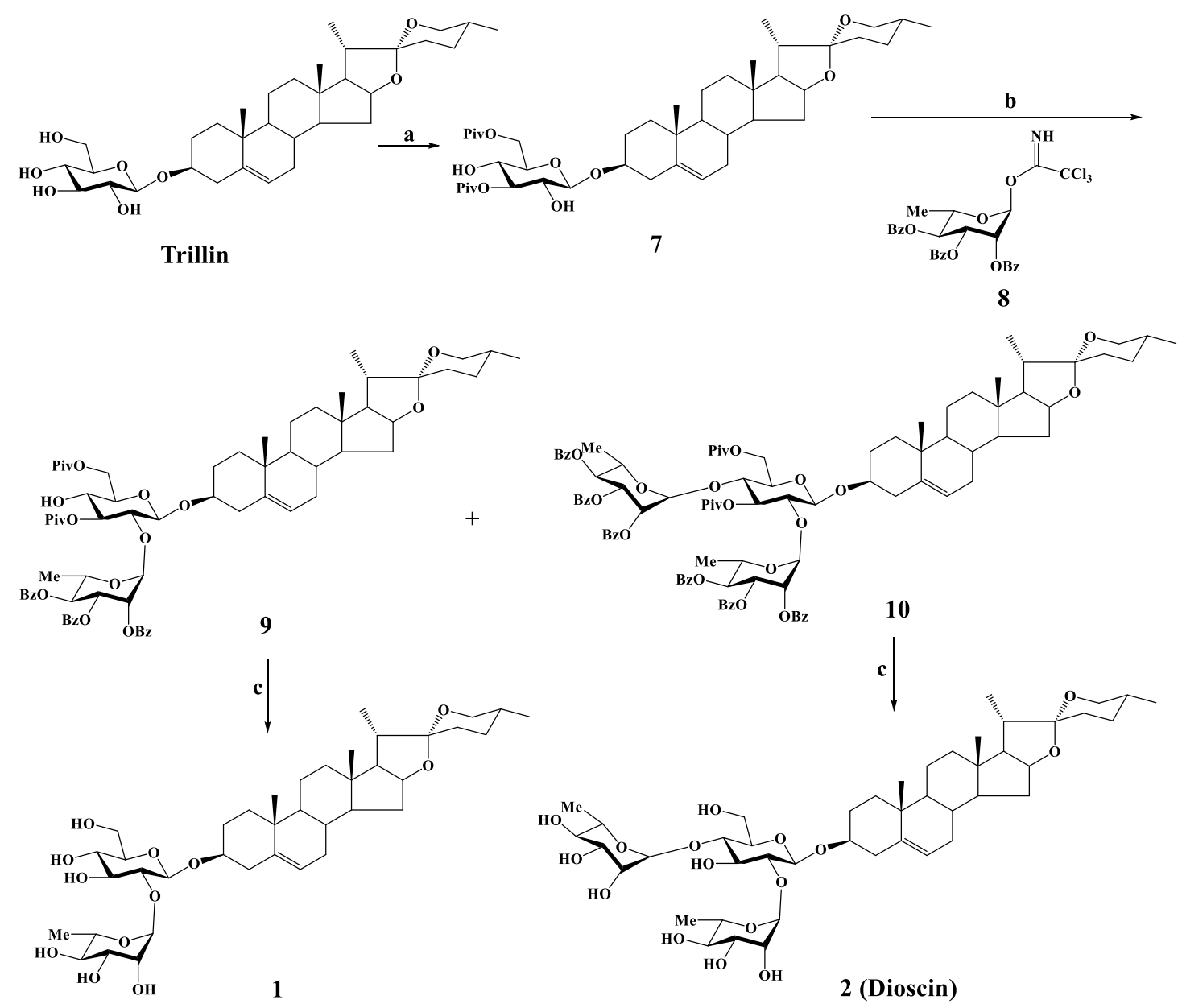

Scheme 1. Synthesis of diosgenyl glycosides $\mathbf{1}$ and $\mathbf{2}$ (dioscin). Reagents and conditions-a: $\mathrm{PivCl}_{2} \mathrm{CH}_{2} \mathrm{Cl}_{2} / \mathrm{Pyridine}(\mathrm{v} / \mathrm{v}=3: 1),-10^{\circ} \mathrm{C}$ to $0{ }^{\circ} \mathrm{C}, 80 \%$; b: $\mathbf{8}(1.2$ equiv), $4 \AA$ MS, TMSOTf $\left(0.2\right.$ equiv), $-60{ }^{\circ} \mathrm{C} ; 50 \%$ for $\mathbf{9}, 32 \%$ for $\mathbf{1 0}$; c: THF/MeOH/ $\mathrm{H}_{2} \mathrm{O}$ (v/v/v=4:4:1), $\mathrm{NaOH}, 45^{\circ} \mathrm{C}, 80 \%$ for $\mathbf{1}, 85 \%$ for 2 (Dioscin).

glucopyranoside), 6 (diosgenyl $\alpha$-L-rhamnopyranosyl-( $1 \rightarrow 2)$-[ $\alpha$ L-rhamnopyranosyl-( $(1 \rightarrow 4)-\alpha$-L-rhamnopyranosyl- $(1 \rightarrow 4)-\alpha-\mathrm{L}-$ rhamnopyranosyl-( $1 \rightarrow 4)-\alpha$-L-rhamnopyranosyl- $(1 \rightarrow 4)]-\beta-D-$ glucopyranoside) were designed and synthesized. Among them, 1-4 were natural products and 5 and $\mathbf{6}$ were first synthesized.
Furthermore, the inhibitory effect of the obtained target molecules against HepG2 cell line (hepatocellular carcinoma cell line) were also evaluated, and the preliminary structure-activity relationship was elucidated. 


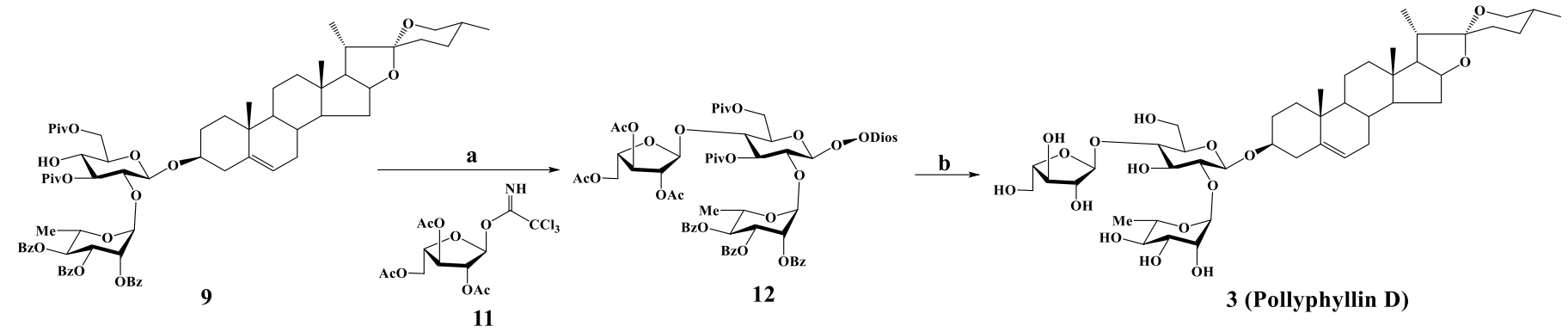

Scheme 2 Synthesis of Polyphyllin D. Reagents and conditions- a: 11 (2.5 equiv), $\mathrm{BF}_{3} \mathrm{Et}_{2} \mathrm{O}$ (0.7 equiv), $4 \AA \mathrm{ASS}^{\mathrm{C}} \mathrm{CH}_{2} \mathrm{Cl}_{2}, 0^{\circ} \mathrm{C}, 93 \%$. b: THF/MeOH/ $\mathrm{H}_{2} \mathrm{O}(\mathrm{v} / \mathrm{v} / \mathrm{v}=$ $4: 4: 1), \mathrm{NaOH}, 45^{\circ} \mathrm{C}, 90 \%$.

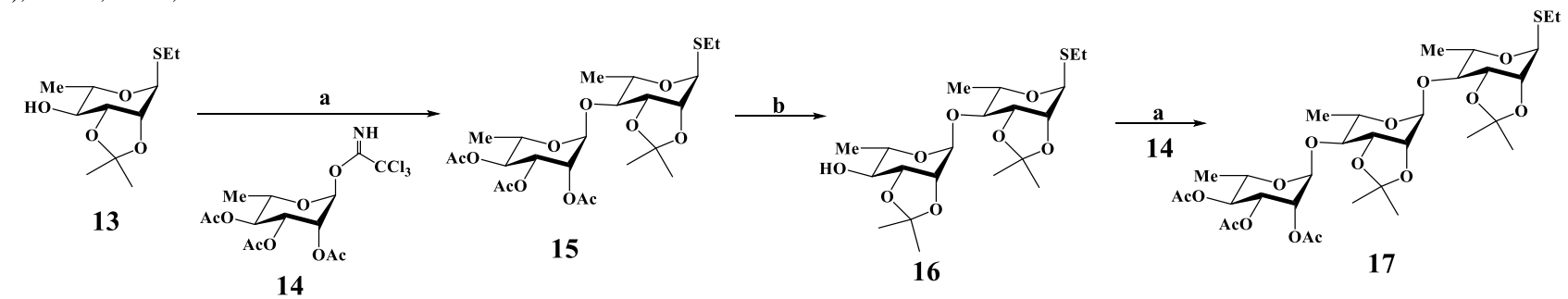
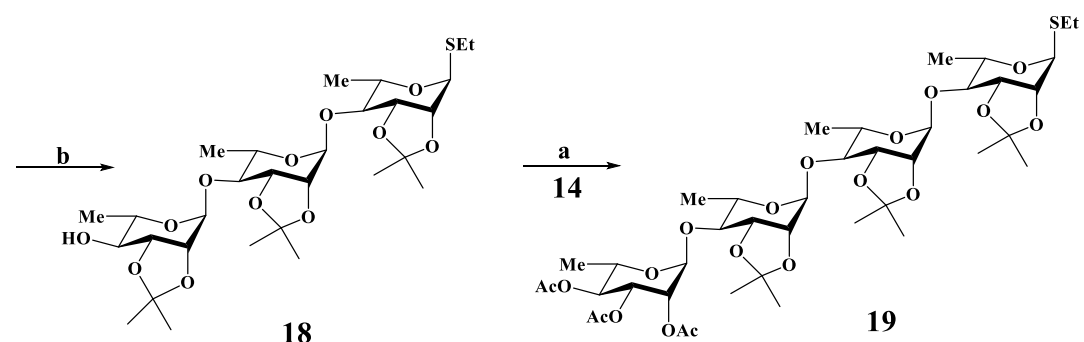

Scheme 3. Synthesis of donors $\mathbf{1 5}, \mathbf{1 7}, \mathbf{1 9}$. Reagents and conditions- a: TMSOTf, $\mathrm{CH}_{2} \mathrm{Cl}_{2}, 4 \AA \mathrm{AS},-78^{\circ} \mathrm{C}$; $92 \%$ for $\mathbf{1 5}, 82 \%$ for $\mathbf{1 7}$ and $83 \%$ for $\mathbf{1 9}$. b: (i) $\mathrm{MeONa} / \mathrm{MeOH}$; (ii) $\mathrm{TsOH} \cdot \mathrm{H}_{2} \mathrm{O}, 2,2$-Dimethoxypropane, $-10{ }^{\circ} \mathrm{C}, 90 \%$ over two steps for $\mathbf{1 6}$ and $88 \%$ for $\mathbf{1 8}$.

Before synthesis, we envisioned that producing two glycosylation products should be more feasible than producing only monoglycosylated products and should facilitate the final purification processes. So, we explored this idea in the preparation of the intermediate $\mathbf{9}$ and $\mathbf{1 0}$. Compound 7, containing unprotected 2,4-hydroxyl groups, was prepared from commercially available trillin (diosgenyl $\alpha$-D-glucopyranoside) according to previous report [22]. As shown in Scheme 1, the synthesis was started from trillin, in the absence of an adjacent axial function, the secondary 3-OH of glucosyl may be more reactive than the secondary $2-\mathrm{OH}$ toward pivaloylation. High selectivity was observed on the pivaloylation of trillin under pivaloyl chloride (PivCl) in $\mathrm{CH}_{2} \mathrm{Cl}_{2}$ /pyridine $(3: 1)$ solution affording the 3,6-di-Pivprotected diol 7 in $80 \%$ yield [23]. Glycosylation of diol 7 with 2,3,4-tri- $O$-benzoyl- $\alpha$-L-rhamnopyranosyl trichloroacetimidate 8 [24] (1.2 equiv, $\left.-60{ }^{\circ} \mathrm{C}\right)$ under the promotion of trimethylsilyl trifluoromethanesulfonate (TMSOTf) (0.2 equiv) gave the 2-O-glycosylated product 9 and 2,4-di- $O$-glycosylated product $\mathbf{1 0}$ in $50 \%$ and $32 \%$ yields, respectively. The presence of an acyl group at the 2-OH position of a sugar donor locks the newly formed glycosidic linkage in the 1,2-trans configuration [24]. Removal of all the acyl protecting groups of $\mathbf{9}$ (benzoyl and pivaloyl groups) under $\mathrm{NaOH}$ in a solvent mixture of $\mathrm{THF} / \mathrm{MeOH} / \mathrm{H}_{2} \mathrm{O}(\mathrm{v} / \mathrm{v} / \mathrm{v}=$ 4:4:1) furnished the naturally existing saponin 1 in $90 \%$ yield. Deprotection of $\mathbf{1 0}$ under similar conditions afforded the desired 2 (dioscin) in good yield $(88 \%)$. The physical data of 2 were identical with those reported [26].
The synthesis of fully protected target molecule polyphyllin D weas commenced with glycosylation between 9 and 2,3,5tri- $O$-acytyl- $\alpha$-L-arabinofuranosyl trichloroacetimidate $\mathbf{1 1}$ [26]. Under the effect of Lewis-acid $\mathrm{BF}_{3} \mathrm{OEt}_{2}$, the conjugation of 9 and $\mathbf{1 1}$ proceeded fluently to afford the fully protected trisaccharide glycoside 12 (90\%). Removal of all the acyl protecting groups of $\mathbf{1 2}$ (acetyl, benzoyl and pivaloyl groups) under $\mathrm{NaOH}$ in a solvent mixture of THF/MeOH/ $\mathrm{H}_{2} \mathrm{O}(\mathrm{v} / \mathrm{v} / \mathrm{v}=$ $4: 4: 1)$ afforded polyphyllin D in $90 \%$ yield, whose data was in good accordance with those reported (Scheme 2) [26]. It is worth mentioning, when we replaced $\mathrm{BF}_{3} \cdot \mathrm{OEt}_{2}$ with TMSOTf [27] as promoter, a mixture of $\alpha(30 \%)$ and $\beta(40 \%) 4-\mathrm{OH}$ glycosylation products were afforded (data not shown).

As shown in Scheme 3, we used the ethylthiogroup as the rhamnose C-1 OH's protection group for easier operation. After protecting the rhamnose $\mathrm{C}-2$ and $\mathrm{C}-3$ hydroxyl with 2,2dimethoxypropane under the promotion of $\mathrm{TsOH}$, we got the acceptor 13. Then the glycosylation of ethyl 2,3-Oisopropylidene-1-thio- $\alpha$-L-rhamnopyranoside 13 with 2,3,4-triO-acetyl- $\alpha$-L-rhamnopyranosyl trichloroacetimidate $\mathbf{1 4}(1.2$ equiv) under the promotion of TMSOTf $\left(0.2\right.$ equiv) at $-78{ }^{\circ} \mathrm{C}$ provided the ethylthio disaccharide 15 (92\%). It is worth mentioning that the glycosylation shoud be performed at $-78^{\circ} \mathrm{C}$. Increased glycosylation temperature leads to intermolecular ethylthio-group transfer by-product [17]. The newly formed $\alpha$ rhamnopyranosyl linkage in $\mathbf{1 5}$ was confirmed by the anomeric signals in its ${ }^{1} \mathrm{H}$ and ${ }^{13} \mathrm{C}$ NMR spectra: $\delta 5.26 \mathrm{ppm}(\mathrm{d}, J=1.2 \mathrm{~Hz}$, $\left.\mathrm{H}-1^{\mathrm{II}}\right)$ and $\delta 95.85 \mathrm{ppm}\left(\mathrm{C}-1^{\mathrm{II}}\right)$. Then, the acetyl group of $\mathbf{1 5}$ was removed under alkaline condition, and then isopropylidene group was used to protect vicinal syn-3,4-diol was further blocked by isopropylidenyl group to furnish $\mathbf{1 6}(90 \%)$. The following steps 


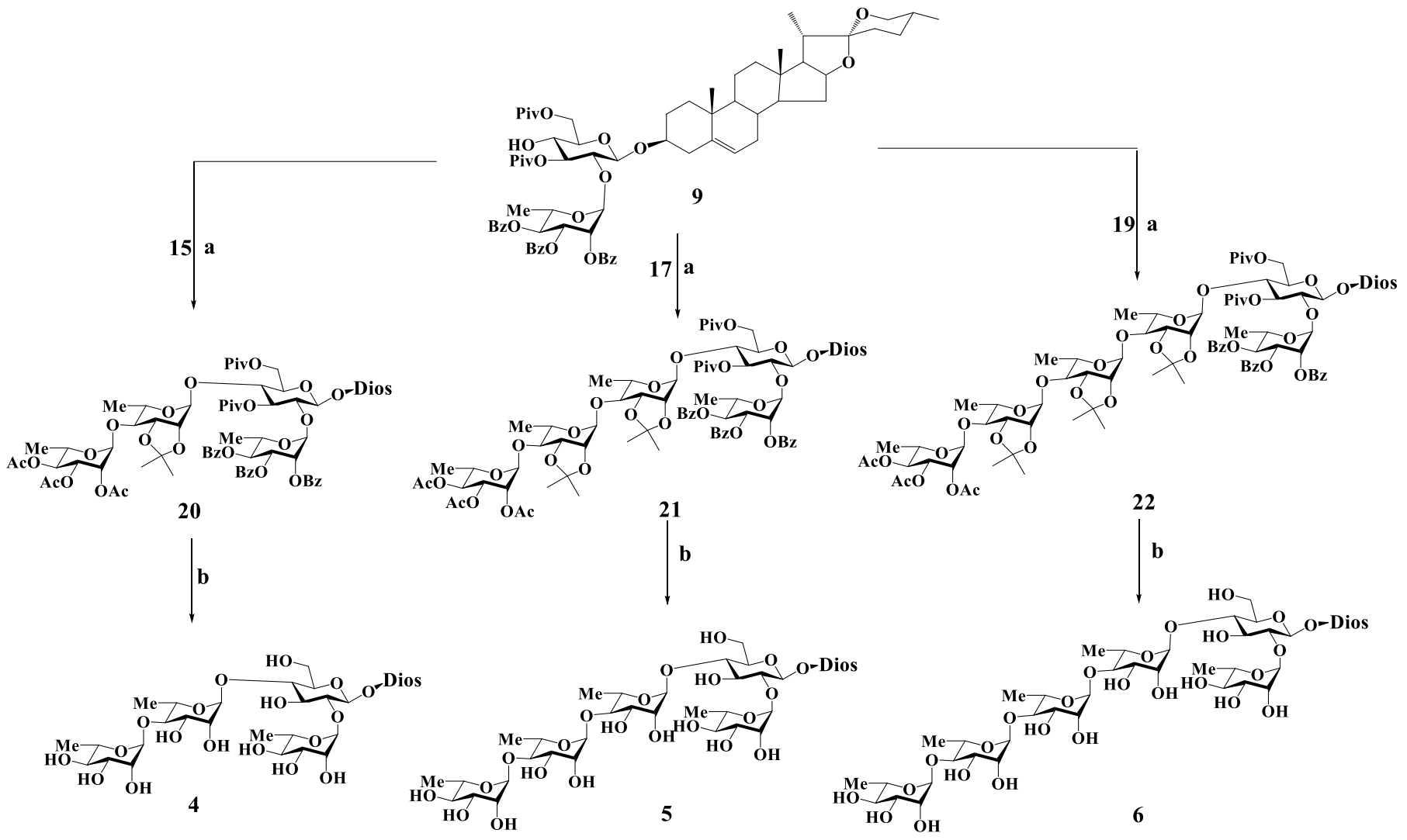

Scheme 4. Synthesis of diosgenyl glycosides 4, 5 and 6. Reagents and conditions- a: donor $\mathbf{1 5}, \mathbf{1 7}$ or $\mathbf{1 9}$, NIS, AgOTf, $4 \AA$ MS, $-10{ }^{\circ} \mathrm{C}$; $87 \%$ for $\mathbf{2 0}, 51 \%$ for $\mathbf{2 1}$ and $60 \%$ for $\mathbf{2 2}$; b: $80 \% \mathrm{AcOH}, 80^{\circ} \mathrm{C}, 5 \mathrm{~h}$; THF/MeOH/ $\mathrm{H}_{2} \mathrm{O}(\mathrm{v} / \mathrm{v} / \mathrm{v}=1: 1: 1), \mathrm{NaOH}, 45^{\circ} \mathrm{C}, 18 \mathrm{~h}, 93 \%$ over two steps for $\mathbf{4}, 90 \%$ for $\mathbf{5}, 88 \%$ for $\mathbf{6}$.

Table 1. Cytotoxicities $\left(\mathrm{IC}_{50}\right.$ ) of Trillin, Dioscin, Polyphyllin D and their analogs against HepG2 Cells ${ }^{\mathrm{a}}$

\begin{tabular}{|c|c|c|c|c|c|c|c|}
\hline Compound & Trillin & 1 & 2 (Dioscin) & 3 (Pollyphyllin D) & 4 & 5 & 6 \\
\hline $\mathrm{IC}_{50}(\mu \mathrm{M})^{\mathrm{b}}$ & $108.7 \pm 8.9$ & $2.92 \pm 0.19$ & $3.09 \pm 0.12$ & $12.17 \pm 1.11$ & $6.33 \pm 0.39$ & $22.84 \pm 3.61$ & $13.42 \pm 0.50$ \\
\hline
\end{tabular}

${ }^{\mathrm{a}}$ HepG2 (liver hepatocellular carcinoma)

${ }^{\mathrm{b}} \mathrm{IC}_{50}$ values (50\% inhibition concentration) represent the means of three independent experiments with SD.

for the preparation of donors $\mathbf{1 7}$ and $\mathbf{1 9}$ followed the same approach as that used for the synthesis of $\mathbf{1 5}$ and $\mathbf{1 6}$. Glycosylation of the acceptor $\mathbf{1 6}$ with the L-rhamnopyranosyl imidate $\mathbf{1 4}$ in the presence of TMSOTf as the catalyst at $-78{ }^{\circ} \mathrm{C}$ afforded the coupling product $\mathbf{1 7}$ in excellent yield (82\%). The newly formed $\alpha$-rhamnopyranosyl linkage in $\mathbf{1 7}$ was confirmed by the anomeric signals in its ${ }^{1} \mathrm{H}$ and ${ }^{13} \mathrm{C}$ NMR spectra: $\delta 5.35$ ppm (br s, H-1 $1^{\mathrm{III}}$ ) and $\delta 95.38 \mathrm{ppm}\left(\mathrm{C}-1^{\mathrm{III}}\right)$. NaOMe mediated saponification delivered triol intermediate and then regioselective protection of the vicinal syn-3,4-diol of the triol intermediate with an isopropylidenyl group to afford acceptor 18 (88\%), which was primed for subsequent sugar chain extension. Thus, upon coupled with rhamnopyranosyl trichloroacetimidate $\mathbf{1 4}$, the trisaccharide glycoside acceptor $\mathbf{1 8}$ was transformed to tetrasaccharide glycoside 19 efficiently (83\%) [28].

With donors and acceptors in hand, we sought to prepare saponin 4-6 followed the approach as shown in Scheme 4. Coupling reaction between saponin acceptor $\mathbf{9}$ and thiodisaccharide 15 was first investigated. Glycosylation of 9 with the ethylthio donor 15 (2.0 equiv) under the action of NISAgOTf gave the expected 2,4-di-O-glycosylated product 20 in satisfactory yield $(87 \%)$. With the successful synthesis of protected saponin 20, we explored to apply the strategy for synthesizing 21 and 22. Under similar conditions, pentasaccharide saponin $\mathbf{2 1}$ was obtained in $51 \%$ yield by coupling of thiotrisaccharide $\mathbf{1 7}$ with $\mathbf{9}$, whereas $20 \%$ of the acceptor 9 was recovered. Glycosylation of 9 with thiotetraaccharide 19 (1.2 equiv) under the same condition provided the desired 22 in lower $60 \%$ yield (compared to the yield of $87 \%$ for $\mathbf{2 0}$ ). Treatment of fully protected steroidal saponins 20-22 with $80 \%$ AcOH to cleave isopropylidene groups, following $\mathrm{NaOH}$ to remove the acyl protecting groups (acetyl, benzoyl and pivaloyl), afforded the desired saponins 4-6 in very good yields (88-93\%). Saponin 4 gave identical analytical data with those reported [28]. The Rha- $(1 \rightarrow 4)-G l u$ linkages, constructed by using donors (17 and 19) without a neighboring participating group, were confirmed to be $\alpha$ configurations by measuring the $J_{\mathrm{C} 1-\mathrm{H} 1}$ values ( 169.7 and $169.5 \mathrm{~Hz}$, respectively) of corresponding rhamnose residues in saponins $\mathbf{5}$ and $\mathbf{6}$.

To date, limited information on the structure activity relationship (SAR) of diosgenyl saponins and their cytotoxicity is available [29]. Although both the aglycone and the carbohydrate moieties are required for the exhibition of their antitumor activity, the exact role of the carbohydrate moiety remains unclear. Thus, with target six compounds in hand, the cytotoxicity of the saponins was evaluated [24, 30-33]. The group of steroidal saponins exhibited a marked structure-dependent growth inhibitory activity against the human hepatocellular carcinoma (HepG2) cells (Table1), which supported that the saccharide group increased the cytotoxicity of trillin, especially for rhamnose. Moderate inhibitory activity was observed for most compounds against HepG2 cell lines, with 
$\mathrm{IC}_{50}$ values in the $\mu \mathrm{M}$ range, varying from $2.92 \mu \mathrm{M}$ for compound 1 to greater than $20 \mu \mathrm{M}$ for compound 5. Diosgenyl $\alpha-\mathrm{L}$ rhamnopyranosyl (1 $\rightarrow 2)$ - $\beta$-D-glucoside 1 showed potent anticancer activities to chosen cell lines, which indicated that the structural modification at the 2'-OH position of the glucose residue appears to affect the potency of its anticancer activity. Additionally, with an $\alpha$-L-rhamnopyranose substituted at 4'-OH (dioscin), the cytotoxicity activities did not change greatly compared to $\mathbf{1}$. However, substituting $\alpha$-L-rhamnopyranose residue at 4 '-OH position with $\alpha$-L-arabinofuranose (polyphyllin D), the cytotoxicity activities reduced to $12.17 \mu \mathrm{M}$, which indicated the importance of rhamnose moiety. Interestingly, extending the sugar chain at 4'-OH with more rhamnose moieties, the diosgenyl pentasaccharide $\mathbf{5}$ and hexasaccharide $\mathbf{6}$ showed cytotoxicity activities of $\mathrm{IC}_{50}$ over $10 \mu \mathrm{mol} / \mathrm{L}$. This may indicate that extending 4'-OH branched with rhamnose moieties do not result in increased anticancer activity toward HepG2 cell. In addition, effects of compound $\mathbf{1}$ and $\mathbf{2}$ on the growth of human normal liver cells L-02 was further investigated and the $\mathrm{IC}_{50}$ values of compound $\mathbf{1}$ and $\mathbf{2}$ was $49.23 \pm 0.06$ and $111.1 \pm 0.19 \mu \mathrm{M}$, respectively. The MTT results indicated compound $\mathbf{1}$ and $\mathbf{2}$ showed no obvious cytotoxicities to human normal liver cells L02 . The action mechanism of the anticancer activity of diosgenyl saponins will be explored in further work.

\section{Conclusions}

In summary, a series of diosgenyl glycosides with 2,4branched oligosaccharide moieties were synthesized in an efficient and practical way. The anticancer activities in vitro of synthesized saponins were evaluated by MTT assay. Moderate cytotoxic activity is found for analogs against HepG2 cells. The result also disclosed that the number and linkage mode of rhamnose moieties have an important effect on the antitumor activities of diosgenyl glycosides. Efforts are currently under way to examine the intercellular target and actions of these saponins by in vitro and in vivo studies.

\section{Experimental}

\subsection{Materials and methods}

${ }^{1} \mathrm{H},{ }^{13} \mathrm{C}$ and nuclear magnetic resonance (NMR) spectra were recorded on a Bruker AVANCE III $(400 \mathrm{MHz})$ spectrometer using $\mathrm{CDCl}_{3}, \mathrm{MeOD}$, DMSO-d6 as the solvent with TMS as an internal standard. Chemical shifts were reported as $\delta$ (ppm) and spin-spin coupling constants as $J(\mathrm{~Hz})$ values. High resolution ESI mass spectra were obtained at a hybrid IT-TOF mass spectrometer (Shimadzu LCMS-IT TOF, Kyoto, Japan). The compounds were stained with $5 \% \mathrm{H}_{2} \mathrm{SO}_{4}$ in ethanol and detection with UV light was employed when possible. Flash column chromatography was performed on silica gel 300 400 mesh. All of the starting materials are commercially available and were used without further purification.

\subsection{Synthesis}

\subsubsection{Diosgenyl 3, 6-di-O-pivaloyl-ß-D-glucopyranoside (7)}

To a solution of trillin (diosgenyl $\beta$-D-glucopyranoside) ( $1 \mathrm{~g}$, $1.73 \mathrm{mmol})$ in $\mathrm{CH}_{2} \mathrm{Cl}_{2}$-pyridine $(3: 1 \mathrm{v} / \mathrm{v}, 8 \mathrm{~mL})$ at $-10{ }^{\circ} \mathrm{C}$ was slowly added pivaloyl chloride $(0.85 \mathrm{~mL}, 6.91 \mathrm{mmol})$. The reaction was monitored by TLC, and the temperature was allowed to warm to $0{ }^{\circ} \mathrm{C}$. When most of the mono-pivaloylated product disappeared, $1 \mathrm{~mL} \mathrm{MeOH}$ was added to quench the reaction. The solvent was removed in vacuo and the residue was diluted with $\mathrm{CH}_{2} \mathrm{Cl}_{2}(20 \mathrm{~mL})$ and then washed with $1 \mathrm{M} \mathrm{HCl}$ solution, saturated aqueous $\mathrm{NaHCO}_{3}$ and brine, respectively. The organic layer was dried over $\mathrm{Na}_{2} \mathrm{SO}_{4}$ and concentrated. The residue was subjected to flash silica gel column chromatography (3:1 petroleum ether-EtOAc) to give 7 $(1.03 \mathrm{~g}, 80 \%)$ as a white foam. $R_{f}=0.50$ (PE: EtOAc, $\left.3: 1\right) ;{ }^{1} \mathrm{H}$ NMR (400 MHz, $\left.\mathrm{CDCl}_{3}\right) \delta 5.35(\mathrm{~d}, 1 \mathrm{H}, J=5.0 \mathrm{~Hz}), 4.85(\mathrm{t}, 1 \mathrm{H}$, $J=9.2 \mathrm{~Hz}), 4.45-4.39(\mathrm{~m}, 3 \mathrm{H}), 4.25(\mathrm{dd}, 1 \mathrm{H}, J=11.8,6.4 \mathrm{~Hz})$, $3.60-3.40(\mathrm{~m}, 5 \mathrm{H}), 3.37(\mathrm{t}, 1 \mathrm{H}, J=10.8 \mathrm{~Hz}), 3.05(\mathrm{~d}, 1 \mathrm{H}, J=4.8)$, 2.42-2.30 (m, 2H), 2.29-2.20 (m, 1H), 2.15-1.90 (m, 3H), 1.89$1.80(\mathrm{q}, 2 \mathrm{H}), 1.79-1.70(\mathrm{q}, 4 \mathrm{H}), 1.69-1.55(\mathrm{~m}, 7 \mathrm{H}), 1.54-1.45(\mathrm{~m}$, $5 \mathrm{H}), 1.26-1.13(\mathrm{~m}, 4 \mathrm{H}), 1.12-0.85(\mathrm{~m}, 9 \mathrm{H}), 0.80-0.70(\mathrm{~d}, 6 \mathrm{H})$. ${ }^{13} \mathrm{C}$ NMR $\left(101 \mathrm{MHz}, \mathrm{CDCl}_{3}\right) \delta 180.24,178.60,140.15,130.88$, $128.81,121.91,109.27,101.22,80.78,79.57,77.93,74.19$, $72.05,70.06,66.83,65.54,63.59,62.07,56.44,50.03,41.58$, $40.24,39.72,39.03,38.82,38.80,37.15,36.82,32.03,31.82$, $31.38,30.54,30.27,29.63,28.77,26.86,20.81,19.33,19.15$, $17.11,16.25,14.50$. HRMS $\mathrm{m} / \mathrm{z}$ calcd for $\mathrm{C}_{43} \mathrm{H}_{69} \mathrm{O}_{10}[\mathrm{M}+\mathrm{H}]^{+}$: 745.4891, found: 745.4848 .

4.2.2 Diosgenyl 2,3,4-tri-O-benzoyl-a-L-rhamnopyranosyl$(1 \rightarrow 2)-3,6-d i-O$-pivaloyl- $\beta$-D-glucopyranoside $(9)$ and diosgenyl

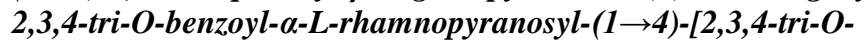
benzoyl- $\alpha-L-r h a m n o p y r a n o s y l-(1 \rightarrow 2)]-3,6-d i-O$-pivaloyl- $\beta-D-$ glucopyranoside (10)

To a suspension of diol 7 (500 mg, $0.67 \mathrm{mmol})$, 2,3,4-tri-Obenzoyl-L-rhamnopyranosyl trichloroacetimidate $8(500 \mathrm{mg}$, $0.81 \mathrm{mmol})$, and $4 \AA \mathrm{AS}(1.0 \mathrm{~g})$ in dry $\mathrm{CH}_{2} \mathrm{Cl}_{2}(15 \mathrm{~mL})$ at -60 ${ }^{\circ} \mathrm{C}$, was added TMSOTf $(24 \mu \mathrm{L}, 0.13 \mathrm{mmol})$. After stirring $2 \mathrm{~h}$ at $-60{ }^{\circ} \mathrm{C}$, the reaction mixture was quenched with $\mathrm{Et}_{3} \mathrm{~N}(0.1 \mathrm{~mL})$ and then filtered and concentrated.

Purification by silica gel column chromatography (petroleum ether: EtOAc, 4:1) gave 9 as a white foam (400 mg, $50 \%)$. $[\alpha]_{\mathrm{D}}$ $+40^{\circ}\left(\mathrm{c} 1.01, \mathrm{CHCl}_{3}\right) ;{ }^{1} \mathrm{H} \mathrm{NMR}\left(400 \mathrm{MHz}, \mathrm{CDCl}_{3}\right) \delta 8.05(\mathrm{~d}, J$ $=7.6 \mathrm{~Hz}, 2 \mathrm{H}), 7.91(\mathrm{~d}, J=7.6 \mathrm{~Hz}, 2 \mathrm{H}), 7.79(\mathrm{~d}, J=7.6 \mathrm{~Hz}$, 2H), $7.60(\mathrm{t}, J=7.4 \mathrm{~Hz}, 1 \mathrm{H}), 7.52-7.45(\mathrm{~m}, 3 \mathrm{H}), 7.40(\mathrm{t}, J=$ $7.4 \mathrm{~Hz}, 1 \mathrm{H}), 7.31(\mathrm{t}, J=7.8 \mathrm{~Hz}, 2 \mathrm{H}), 7.26-7.22(\mathrm{~m}, 2 \mathrm{H})$, $5.76(\mathrm{dd}, J=10.0,3.2 \mathrm{~Hz}, 1 \mathrm{H}), 5.63(\mathrm{t}, J=10.0 \mathrm{~Hz}, 2 \mathrm{H}), 5.43$ (d, $J=4.4 \mathrm{~Hz}, 1 \mathrm{H}), 5.23(\mathrm{~s}, 1 \mathrm{H}), 5.18(\mathrm{t}, J=9.4 \mathrm{~Hz}, 1 \mathrm{H}), 4.79$ $(\mathrm{dq}, J=12.2,6.0 \mathrm{~Hz}, 1 \mathrm{H}), 4.69(\mathrm{~d}, J=7.8 \mathrm{~Hz}, 1 \mathrm{H}), 4.48-$ $4.39(\mathrm{~m}, 3 \mathrm{H}), 4.26(\mathrm{dd}, J=11.8,6.8 \mathrm{~Hz}, 1 \mathrm{H}), 3.84(\mathrm{t}, J=8.4$ $\mathrm{Hz}, 1 \mathrm{H}), 3.65$ (ddd, $J=17.0,10.4,4.6 \mathrm{~Hz}, 2 \mathrm{H}), 3.50-3.35$ $(\mathrm{m}, 4 \mathrm{H}), 3.06(\mathrm{~d}, J=6.0 \mathrm{~Hz}, 1 \mathrm{H}), 2.60-2.52(\mathrm{~m}, 1 \mathrm{H}), 2.42(\mathrm{t}$, $J=12.6 \mathrm{~Hz}, 1 \mathrm{H}), 2.05-1.98(\mathrm{~m}, 3 \mathrm{H}), 1.86-1.73(\mathrm{~m}, 5 \mathrm{H})$, $1.62(\mathrm{~d}, J=13.8 \mathrm{~Hz}, 6 \mathrm{H}), 1.35(\mathrm{~d}, J=6.2 \mathrm{~Hz}, 3 \mathrm{H}), 1.22(\mathrm{t}, J=$ $7.8 \mathrm{~Hz}, 15 \mathrm{H}), 1.17(\mathrm{~s}, 8 \mathrm{H}), 0.98(\mathrm{~d}, J=6.8 \mathrm{~Hz}, 3 \mathrm{H}), 0.93(\mathrm{~s}$, $3 \mathrm{H}), 0.79(\mathrm{~d}, J=6.2 \mathrm{~Hz}, 7 \mathrm{H}) .{ }^{13} \mathrm{C} \mathrm{NMR}\left(101 \mathrm{MHz}, \mathrm{CDCl}_{3}\right) \delta$ $179.90,178.53$, 167.66, 165.62, 165.39, 165.15, 139.99, 133.39, $133.19,132.99,132.26,130.86,129.78,129.72,129.62,129.15$, $128.79,128.53,128.30,128.18,122.10,109.23,101.19,99.96$, $97.61,80.75,79.73,78.89,74.56,74.08,71.74,71.01,70.34$, $69.85,66.80,66.70,65.71,63.59,62.07,56.37,49.98,41.57$, $40.22,39.65,38.98,38.81,38.78,37.11,36.78,32.08,31.85$, $31.45,31.36,30.51,30.24,29.86,29.63,28.76,27.13,26.85$, $20.75,19.19,19.13,17.35,17.09,16.23,14.49,13.67$. HRMS $\mathrm{m} / \mathrm{z}$ calcd for $\mathrm{C}_{70} \mathrm{H}_{90} \mathrm{O}_{17} \mathrm{Na} \quad[\mathrm{M}+\mathrm{Na}]^{+}:$1225.6070, found: 1225.6026

Purification by silica gel column chromatography (petroleum ether: EtOAc, 6:1) gave 10 as a white foam (360 mg, $32 \%)$. $[\alpha]_{\mathrm{D}}$ $+64^{\circ}$ (c 1.0, $\left.\mathrm{CHCl}_{3}\right) ;{ }^{1} \mathrm{H}$ NMR $\left(400 \mathrm{MHz}, \mathrm{CDCl}_{3}\right) \delta$ 8.05-7.95 $(\mathrm{m}, 4 \mathrm{H}), 7.90(\mathrm{~s}, 1 \mathrm{H}), 7.89(\mathrm{~s}, 1 \mathrm{H}), 7.86(\mathrm{~s}, 1 \mathrm{H}), 7.84(\mathrm{~s}, 1 \mathrm{H})$, $7.73(\mathrm{~d}, J=7.8 \mathrm{~Hz}, 2 \mathrm{H}), 7.64(\mathrm{t}, J=6.6 \mathrm{~Hz}, 1 \mathrm{H}), 7.52(\mathrm{dd}, J=$ 9.2, 4.8 Hz, 2H), $7.47-7.07(\mathrm{~m}, 17 \mathrm{H}), 5.74-5.67(\mathrm{~m}, 1 \mathrm{H})$, 
$5.67-5.62(\mathrm{~m}, 1 \mathrm{H}), 5.62-5.57(\mathrm{~m}, 1 \mathrm{H}), 5.54(\mathrm{dd}, J=16.4$, $6.8 \mathrm{~Hz}, 1 \mathrm{H}), 5.46(\mathrm{~s}, 1 \mathrm{H}), 5.42(\mathrm{~d}, J=7.7 \mathrm{~Hz}, 1 \mathrm{H}), 5.38(\mathrm{~d}, J$ $=5.2 \mathrm{~Hz}, 1 \mathrm{H}), 5.22(\mathrm{~s}, 1 \mathrm{H}), 5.15(\mathrm{~s}, 1 \mathrm{H}), 5.09(\mathrm{~s}, 1 \mathrm{H}), 4.71(\mathrm{t}$, $J=8.4 \mathrm{~Hz}, 1 \mathrm{H}), 4.68-4.61(\mathrm{~m}, 1 \mathrm{H}), 4.56(\mathrm{~d}, J=12.0 \mathrm{~Hz}$, $1 \mathrm{H}), 4.34$ (dt, $J=21.0,6.2 \mathrm{~Hz}, 2 \mathrm{H}), 4.26-4.20(\mathrm{~m}, 1 \mathrm{H}), 3.92$ $-3.83(\mathrm{~m}, 1 \mathrm{H}), 3.74(\mathrm{dd}, J=14.6,7.2 \mathrm{~Hz}, 1 \mathrm{H}), 3.67-3.56$ $(\mathrm{m}, 1 \mathrm{H}), 3.40(\mathrm{t}, J=10.4 \mathrm{~Hz}, 1 \mathrm{H}), 3.31(\mathrm{t}, J=10.8 \mathrm{~Hz}, 1 \mathrm{H})$, $2.52(\mathrm{~d}, J=10.4 \mathrm{~Hz}, 1 \mathrm{H}), 2.38-2.28(\mathrm{~m}, 1 \mathrm{H}), 1.99-1.91$ $(\mathrm{m}, 2 \mathrm{H}), 1.84-1.33(\mathrm{~m}, 15 \mathrm{H}), 1.32-1.21(\mathrm{~m}, 8 \mathrm{H}), 1.20-$ $1.12(\mathrm{~m}, 12 \mathrm{H}), 1.11-0.97(\mathrm{~m}, 9 \mathrm{H}), 0.95-0.83(\mathrm{~m}, 7 \mathrm{H}), 0.79$ $-0.65(\mathrm{~m}, 6 \mathrm{H}) .{ }^{13} \mathrm{C}$ NMR $\left(101 \mathrm{MHz}, \mathrm{CDCl}_{3}\right) \delta 177.87,176.63$, 165.77, 165.67, 165.40, 165.34, 165.18, 165.06, 140.08, 133.39, 133.30, 133.27, 133.21, 133.16, 133.03, 132.95, 132.79, 130.88, $129.89,129.82,129.77,129.73,129.67,129.61,129.41,129.35$, $129.30,129.25,129.22,128.81,128.54,128.51,128.39,128.33$, $128.30,128.22,128.17,128.06,109.26,99.44,97.36,80.79$, $79.26,76.32,75.59,72.53,71.90,71.84,71.33,70.95,70.46$, $69.88,69.72,69.63,68.27,66.82,65.54,62.09,56.41,50.01$, $41.59,40.25,39.68,38.87,38.60,37.16,36.82,32.12,31.87$, $31.47,31.39,30.54,30.27,29.83,28.78,27.18,26.93,20.77$, $19.23,19.15,17.73,17.48,17.11,16.25,14.50,13.69$. HRMS $\mathrm{m} / \mathrm{z}$ calcd for $\mathrm{C}_{97} \mathrm{H}_{113} \mathrm{O}_{24}[\mathrm{M}+\mathrm{H}]^{+}:$: 1661.7622, found: 1661.7627 .

\subsubsection{Diosgenyl $\quad \alpha-L-r h a m n o p y r a n o s y l-(1 \rightarrow 2)-\quad \beta-D$ - glucopyranoside (1)}

Compound 9 (50 mg) was dissolved in a solution of $\mathrm{CH}_{3} \mathrm{OH}-$ THF- $\mathrm{H}_{2} \mathrm{O}(9 \mathrm{~mL}, \mathrm{v} / \mathrm{v} / \mathrm{v}=4: 4: 1)$, then $\mathrm{NaOH}$ was added to get $\mathrm{pH}$ 11.0. The solution, kept overnight at room temperature, was neutralized with Dowex-50 $\left(\mathrm{H}^{+}\right)$resin, filtered, and concentrated. Chromatography of the residue on a silica gel column $\left(\mathrm{CH}_{2} \mathrm{Cl}_{2}\right.$ : $\mathrm{CH}_{3} \mathrm{OH}$ 10:1-3:1) gave compound 1 as white solid (24 mg, 80\%). $[\alpha]_{\mathrm{D}}-96^{\circ}$ (c 1.0, pyridine); ${ }^{1} \mathrm{H}$ NMR $\left(400 \mathrm{MHz}, \mathrm{C}_{5} \mathrm{D}_{5} \mathrm{~N}\right) \delta 6.40$ $(\mathrm{s}, 1 \mathrm{H}), 5.31(\mathrm{~d}, J=3.8 \mathrm{~Hz}, 1 \mathrm{H}), 5.07-4.96(\mathrm{~m}, 2 \mathrm{H}), 4.86(\mathrm{~s}$, $1 \mathrm{H}), 4.65(\mathrm{dd}, J=9.2,3.0 \mathrm{~Hz}, 1 \mathrm{H}), 4.59-4.49(\mathrm{~m}, 2 \mathrm{H}), 4.46$ $-4.34(\mathrm{~m}, 2 \mathrm{H}), 4.28(\mathrm{dd}, J=10.4,7.4 \mathrm{~Hz}, 2 \mathrm{H}), 4.18(\mathrm{t}, J=$ $8.8 \mathrm{~Hz}, 1 \mathrm{H}), 4.01-3.84(\mathrm{~m}, 2 \mathrm{H}), 3.64-3.45(\mathrm{~m}, 2 \mathrm{H}), 2.86-$ $2.70(\mathrm{~m}, 2 \mathrm{H}), 2.15(\mathrm{~d}, J=11.2 \mathrm{~Hz}, 1 \mathrm{H}), 2.09-2.00(\mathrm{~m}, 1 \mathrm{H})$, $1.98-1.83(\mathrm{~m}, 3 \mathrm{H}), 1.78(\mathrm{~d}, J=6.2 \mathrm{~Hz}, 3 \mathrm{H}), 1.74-1.67(\mathrm{~m}$, $3 \mathrm{H}), 1.61-1.52(\mathrm{~m}, 4 \mathrm{H}), 1.49-1.40(\mathrm{~m}, 3 \mathrm{H}), 1.26(\mathrm{t}, J=7.4$ $\mathrm{Hz}, 9 \mathrm{H}), 1.15$ (d, J = 7.2 Hz, 3H), 1.07 (s, 4H), 1.01-0.88 (m, $2 \mathrm{H}), 0.85(\mathrm{~s}, 3 \mathrm{H}), 0.70(\mathrm{~d}, J=4.8 \mathrm{~Hz}, 3 \mathrm{H}),{ }^{13} \mathrm{C}$ NMR $(101$ $\left.\mathrm{MHz}, \mathrm{C}_{5} \mathrm{D}_{5} \mathrm{~N}\right) \delta 141.24,122.12,109.64,102.33,100.73$, 81.50, 79.98, 78.65, 78.30, 74.43, 73.19, 72.96, 72.15, 69.85, $67.25,63.28,62.99,57.02,50.66,46.15,42.36,40.85,40.24$, $39.37,37.90,37.53,32.70,32.22,32.08,30.99,30.58,29.66$, $21.48,19.80,19.07,17.71,16.72,15.43,8.98$. HRMS m/z calcd for $\mathrm{C}_{39} \mathrm{H}_{62} \mathrm{O}_{12} \mathrm{Na}[\mathrm{M}+\mathrm{Na}]^{+}$: 745.4133, found: 745.4179.

\subsubsection{Diosgenyl $\quad \alpha$-L-rhamnopyranosyl-( $1 \rightarrow 4)-[\alpha-L-$ rhamnopyranosyl-(1 $\rightarrow 2)]-\beta$-D-glucopyranoside (2)}

Carried out using same procedure as for $\mathbf{1}$ to give 2 (dioscin) (85\% yield) as a white solid. $[\alpha]_{\mathrm{D}}+102^{\circ}(c$ 1.0, $\mathrm{MeOH}) ;{ }^{1} \mathrm{H}$ NMR (400 MHz, $\left.\mathrm{C}_{5} \mathrm{D}_{5} \mathrm{~N}\right) \delta 6.41(\mathrm{~s}, 1 \mathrm{H}), 5.87(\mathrm{~s}$, $1 \mathrm{H}), 5.31(\mathrm{~d}, J=4.4 \mathrm{~Hz}, 1 \mathrm{H}), 5.03-4.91(\mathrm{~m}, 3 \mathrm{H}), 4.89$ (d, $J=2.0$ $\mathrm{Hz}, 1 \mathrm{H}), 4.72(\mathrm{~s}, 1 \mathrm{H}), 4.64(\mathrm{dd}, J=9.2,3.2 \mathrm{~Hz}, 2 \mathrm{H}), 4.59-4.52$ $(\mathrm{m}, 2 \mathrm{H}), 4.45-4.34(\mathrm{~m}, 3 \mathrm{H}), 4.25-4.17(\mathrm{~m}, 3 \mathrm{H}), 4.08$ (dd, $J=12.0$, $2.8 \mathrm{~Hz}, 1 \mathrm{H}), 3.92-3.80(\mathrm{~m}, 1 \mathrm{H}), 3.62(\mathrm{t}, J=9.6 \mathrm{~Hz}, 1 \mathrm{H}), 3.51(\mathrm{t}$, $J=10.0 \mathrm{~Hz}, 1 \mathrm{H}), 2.86-2.66(\mathrm{~m}, 2 \mathrm{H}), 2.10-2.00(\mathrm{~m}, 2 \mathrm{H}), 1.96(\mathrm{t}, J$ $=6.8 \mathrm{~Hz}, 1 \mathrm{H}), 1.91-1.80(\mathrm{~m}, 3 \mathrm{H}), 1.79-1.74(\mathrm{~d}, J=6.0 \mathrm{~Hz}, 3 \mathrm{H})$, 1.73-1.66 (m, 3H), $1.62(\mathrm{~d}, J=6.4 \mathrm{~Hz}, 3 \mathrm{H}), 1.59(\mathrm{~d}, J=4.2 \mathrm{~Hz}$, $3 \mathrm{H}), 1.52(\mathrm{~s}, 1 \mathrm{H}), 1.48-1.41(\mathrm{~m}, 3 \mathrm{H}), 1.26(\mathrm{t}, J=7.2 \mathrm{~Hz}, 8 \mathrm{H})$, $1.15(\mathrm{~d}, J=7.2 \mathrm{~Hz}, 3 \mathrm{H}), 1.06(\mathrm{~s}, 3 \mathrm{H}), 1.00-0.89(\mathrm{~m}, 2 \mathrm{H}), 0.84(\mathrm{~s}$, $3 \mathrm{H}), 0.70(\mathrm{~d}, J=4.8 \mathrm{~Hz}, 3 \mathrm{H}) .{ }^{13} \mathrm{C}$ NMR $\left(101 \mathrm{MHz}, \mathrm{CDCl}_{3}\right) \delta$ $141.18,122.17,109.65,103.16,102.22,100.65,81.49$, 78.89,
$78.47,78.26,78.05,77.31,74.35,74.20,73.15,73.08,72.90$, $70.75,69.86,67.25,63.28,61.59,57.02,50.68,46.18,42.36$, $40.85,40.24,39.35,37.88,32.70,32.61,32.22,32.07,30.99$, $30.54,29.66,21.49,19.79,19.02,18.88,17.72,16.73,15.43$, 9.02. HRMS m/z calcd for $\mathrm{C}_{45} \mathrm{H}_{72} \mathrm{O}_{16} \mathrm{Na}[\mathrm{M}+\mathrm{Na}]^{+}$: 891.4718, found: 891.4738 .

4.2.5 Diosgenyl 2,4,5-tri-O-acetyl- $\alpha$-L-arabinofuranosyl-( $1 \rightarrow 4)$ [2,3,4-tri-O-benzoyl- $\alpha$-L-rhamnopyranosyl- $(1 \rightarrow 2)]-3,6-d i-O$ pivaloyl- $\beta$-D-glucopyranoside (12)

To a suspension of 2,3,5-tri- $O$-acetyl- $\alpha$-L-arabinofuranosyltrichloroacetimidate $11(0.14 \mathrm{~g}, 0.33 \mathrm{mmol}), 9(0.16 \mathrm{~g}, 0.13$ mmol) and $4 \AA \mathrm{MS}(0.2 \mathrm{~g})$ in $\operatorname{dry} \mathrm{CH}_{2} \mathrm{Cl}_{2}(5 \mathrm{~mL})$ at $0^{\circ} \mathrm{C}$, was slowly added $\mathrm{BF}_{3} \cdot \mathrm{Et}_{2} \mathrm{O}(12 \mu \mathrm{L}, 0.1 \mathrm{mmol})$. After being stirred for $2 \mathrm{~h}$, the reaction was quenched with $\mathrm{Et}_{3} \mathrm{~N}(0.1 \mathrm{~mL})$ and then filtered and concentrated. Chromatography of the residue on a silica gel column (5:1 petroleum ether- EtOAc) afforded the compound $12(180 \mathrm{mg}, 93 \%)$ as a white amorphous solid. $[\alpha]_{\mathrm{D}}$ $+15.5^{\circ}\left(c 1.01, \mathrm{CHCl}_{3}\right) ;{ }^{1} \mathrm{H}$ NMR $\left(400 \mathrm{MHz}, \mathrm{CDCl}_{3}\right) \delta 8.03(\mathrm{~d}$, $J=7.2 \mathrm{~Hz}, 2 \mathrm{H}), 7.92(\mathrm{t}, J=9.6 \mathrm{~Hz}, 2 \mathrm{H}), 7.78(\mathrm{dd}, J=9.8,4.3$ $\mathrm{Hz}, 2 \mathrm{H}), 7.59$ (t, $J=7.4 \mathrm{~Hz}, 1 \mathrm{H}), 7.53-7.45(\mathrm{~m}, 3 \mathrm{H}), 7.41-$ $7.38(\mathrm{~m}, 1 \mathrm{H}), 7.31(\mathrm{t}, J=7.8 \mathrm{~Hz}, 2 \mathrm{H}), 7.23(\mathrm{t}, J=7.8 \mathrm{~Hz}$, $2 \mathrm{H}), 5.79-5.70(\mathrm{~m}, 1 \mathrm{H}), 5.64-5.56(\mathrm{~m}, 2 \mathrm{H}), 5.42(\mathrm{t}, J=8.5$ $\mathrm{Hz}, 2 \mathrm{H}), 5.16(\mathrm{~d}, J=5.8 \mathrm{~Hz}, 2 \mathrm{H}), 5.02(\mathrm{~d}, J=1.3 \mathrm{~Hz}, 1 \mathrm{H})$, $4.98-4.95(\mathrm{~m}, 1 \mathrm{H}), 4.68(\mathrm{~d}, J=7.6 \mathrm{~Hz}, 1 \mathrm{H}), 4.54(\mathrm{~d}, J=$ $10.1 \mathrm{~Hz}, 1 \mathrm{H}), 4.45-4.40(\mathrm{~m}, 1 \mathrm{H}), 4.33-4.27(\mathrm{~m}, 2 \mathrm{H}), 4.19$ $-4.14(\mathrm{~m}, 2 \mathrm{H}), 3.81(\mathrm{q}, J=7.7 \mathrm{~Hz}, 2 \mathrm{H}), 3.66(\mathrm{dt}, J=9.3,6.6$ $\mathrm{Hz}, 2 \mathrm{H}), 3.47(\mathrm{~d}, J=13.2 \mathrm{~Hz}, 1 \mathrm{H}), 3.37(\mathrm{t}, J=10.9 \mathrm{~Hz}, 1 \mathrm{H})$, $2.55(\mathrm{dd}, J=13.0,2.8 \mathrm{~Hz}, 1 \mathrm{H}), 2.39(\mathrm{t}, J=12.6 \mathrm{~Hz}, 1 \mathrm{H}), 2.10$ $(\mathrm{d}, J=2.8 \mathrm{~Hz}, 6 \mathrm{H}), 2.07(\mathrm{~d}, J=2.6 \mathrm{~Hz}, 3 \mathrm{H}), 2.00(\mathrm{dd}, J=$ 11.6, $3.8 \mathrm{~Hz}, 2 \mathrm{H}), 1.80-1.74(\mathrm{~m}, 3 \mathrm{H}), 1.65-1.57(\mathrm{~m}, 6 \mathrm{H})$, $1.34(\mathrm{~d}, J=6.3 \mathrm{~Hz}, 3 \mathrm{H}), 1.25(\mathrm{~s}, 7 \mathrm{H}), 1.22(\mathrm{~s}, 10 \mathrm{H}), 1.20(\mathrm{~s}$, $1 \mathrm{H}), 1.14(\mathrm{~s}, 9 \mathrm{H}), 0.97(\mathrm{~d}, J=6.8 \mathrm{~Hz}, 3 \mathrm{H}), 0.92(\mathrm{~s}, 3 \mathrm{H}), 0.86$ $(\mathrm{dd}, J=6.4,2.2 \mathrm{~Hz}, 3 \mathrm{H}), 0.78(\mathrm{~d}, J=6.8 \mathrm{~Hz}, 6 \mathrm{H}) .{ }^{13} \mathrm{C} \mathrm{NMR}$ $\left(101 \mathrm{MHz}, \mathrm{CDCl}_{3}\right) \delta 177.92,176.80,170.56,170.30,169.57$, $165.68,165.38,165.14,140.07,133.42,133.25,133.01$, $129.86,129.79,129.69,129.37,129.32,129.26,128.68$, $128.58,128.37,128.22,127.20,122.15,109.30,105.71$, $99.65,97.46,81.42,80.82,79.54,77.26,76.57,76.00,74.47$, $72.80,71.80,70.38,69.93,66.87,66.82,63.15,63.06,62.14$, 56.44, 50.05, 41.64, 40.29, 39.72, 38.85, 38.80, 38.72, 37.19, $36.86,32.14,31.91,31.51,31.43,30.31,29.88,28.83,27.20$, $27.11,26.93,20.82,20.76,20.73,20.70,19.27,17.48,17.16$, 16.30, 14.55. HRMS $\mathrm{m} / \mathrm{z}$ calcd for $\mathrm{C}_{81} \mathrm{H}_{105} \mathrm{O}_{24}[\mathrm{M}+\mathrm{H}]^{+}$: 1461.6996, found: 1461.6924 .

4.2.6 Diosgenyl a-L- rhamnopyranosyl- $(1 \rightarrow 2)-[(a-L-$ arabinofuranosyl)- $(1 \rightarrow 4)]-\beta$-D-glucopyranoside $(3)$

Carried out using same procedure as for $\mathbf{1}$ to give 3 (polyphyllin D) (90\% yield) as a white solid. $[\alpha]_{\mathrm{D}}+116^{\circ}(c$ $\left.0.52, \mathrm{CH}_{3} \mathrm{OH}\right) .{ }^{1} \mathrm{H} \mathrm{NMR}\left(400 \mathrm{MHz}, \mathrm{CD}_{3} \mathrm{OD} / \mathrm{CDCl}_{3}\right) \delta 5.42(\mathrm{~d}, J$ $=2.4 \mathrm{~Hz}, 1 \mathrm{H}), 5.28(\mathrm{~s}, 1 \mathrm{H}), 5.09(\mathrm{~s}, 1 \mathrm{H}), 4.54(\mathrm{~d}, J=7.6 \mathrm{~Hz}, 1 \mathrm{H})$, $4.46(\mathrm{q}, 1 \mathrm{H}), 4.21-4.12(\mathrm{~m}, 2 \mathrm{H}), 4.05(\mathrm{~s}, 1 \mathrm{H}), 3.99(\mathrm{~s}, 1 \mathrm{H}), 3.94(\mathrm{t}$, $J=4.4 \mathrm{~Hz}, 1 \mathrm{H}), 3.91-3.87(\mathrm{~m}, 1 \mathrm{H}), 3.84-3.65(\mathrm{~m}, 6 \mathrm{H}), 3.59(\mathrm{t}, J$ $=9.6 \mathrm{~Hz}, 1 \mathrm{H}), 3.54-3.44(\mathrm{~m}, 3 \mathrm{H}), 3.42-3.36(\mathrm{~m}, 5 \mathrm{H}), 2.48(\mathrm{~d}, J=$ $13.2 \mathrm{~Hz}, 1 \mathrm{H}), 2.34(\mathrm{t}, J=11.6 \mathrm{~Hz}, 1 \mathrm{H}), 2.08-1.90(\mathrm{~m}, 6 \mathrm{H}), 1.81$ $(\mathrm{t}, J=8.0 \mathrm{~Hz}, 3 \mathrm{H}), 1.73-1.55(\mathrm{~m}, 9 \mathrm{H}), 1.42-1.28(\mathrm{~m}, 12 \mathrm{H}), 1.09$ $(\mathrm{s}, 3 \mathrm{H}), 1.02(\mathrm{~d}, J=6.8 \mathrm{~Hz}, 3 \mathrm{H}), 0.88-0.83(\mathrm{~m}, 6 \mathrm{H}) .{ }^{13} \mathrm{C} \mathrm{NMR}$ $\left(101 \mathrm{MHz}, \mathrm{MeOD} / \mathrm{CDCl}_{3}\right) \delta \delta 141.23,122.22,110.19,109.36$, 101.45, 99.98, 85.50, 82.37, 81.70, 78.75, 77.94, 77.46, 77.19, $75.88,73.40,71.86,71.55,69.14,67.42,62.98,62.49,61.37$, 57.26, 51.03, 42.36, 40.93, 40.41, 39.03, 38.00, 37.52, 32.70, $32.27,32.21,31.91,30.88,30.26,30.21,29.33,21.49,19.54$, 17.62, 17.24, 16.55, 14.63. HRMS m/z calcd for $\mathrm{C}_{44} \mathrm{H}_{70} \mathrm{O}_{16} \mathrm{Na}$ $[\mathrm{M}+\mathrm{Na}]^{+}:$877.4562, found: 877.4566 . 
4.2.7 Ethyl 2,3,4-tri-O-acetyl- $\alpha$-L-rhamnopyranosyl-(1 $\rightarrow 4)-2,3-$ O-isopropylidene-1-thio- $\alpha$-L-rhamnopyranoside (15)

To a suspension of 2,3,4-tri-O-acetyl- $\alpha$-L-rhamnopyranosyltri-chloroacetimidate 14 (1.04 g, $2.4 \mathrm{mmol}), 13(0.5 \mathrm{~g}, 2 \mathrm{mmol})$ and $4 \AA \mathrm{AS}(1.0 \mathrm{~g})$ in $\operatorname{dry} \mathrm{CH}_{2} \mathrm{Cl}_{2}(10 \mathrm{~mL})$ at $-78{ }^{\circ} \mathrm{C}$, was slowly added TMSOTf $(18 \mu \mathrm{L}, 0.1 \mathrm{mmol})$. After being stirred for $2 \mathrm{~h}$, the reaction was quenched with $\mathrm{Et}_{3} \mathrm{~N}(0.1 \mathrm{~mL})$ and then filtered and concentrated. The residue was purified by silica gel column chromatography (petroleum ether-EtOAc, 8:1) gave 15 (0.97 g, $92 \%)$ as a white syrup. $[\alpha]_{\mathrm{D}}-156^{\circ}\left(c 1.0, \mathrm{CHCl}_{3}\right) ;{ }^{1} \mathrm{H}$ NMR $(400$ $\left.\mathrm{MHz} ; \mathrm{CDCl}_{3}\right) 5.44(\mathrm{~s}, 1 \mathrm{H}), 5.26(\mathrm{~d}, J=1.2 \mathrm{~Hz}, 1 \mathrm{H}), 5.25-5.22(\mathrm{~m}$ $1 \mathrm{H}), 5.14(\mathrm{dd}, J=10.0,3.2 \mathrm{~Hz}, 1 \mathrm{H}), 5.00(\mathrm{t}, J=9.6 \mathrm{~Hz}, 1 \mathrm{H})$, 4.15-4.05 (m, 2H), 4.05-3.98 (m, 1H), $3.81(\mathrm{dq}, J=12.6,6.2$ $\mathrm{Hz}, 1 \mathrm{H}), 3.49(\mathrm{dd}, J=9.8,7.2 \mathrm{~Hz}, 1 \mathrm{H}), 2.63-2.56(\mathrm{~m}, 1 \mathrm{H})$, 2.52-2.45 (m, 1H), $2.09(\mathrm{~s}, 3 \mathrm{H}), 1.99(\mathrm{~s}, 3 \mathrm{H}), 1.92(\mathrm{~s}, 3 \mathrm{H}), 1.46$ $(\mathrm{s}, 3 \mathrm{H}), 1.27-1.22(\mathrm{~m}, 9 \mathrm{H}), 1,17-1.14(\mathrm{~m}, 3 \mathrm{H}) .{ }^{13} \mathrm{C}$ NMR $(101$ $\left.\mathrm{MHz}, \mathrm{CDCl}_{3}\right) \delta 170.01,169.94,109.55,95.85,81.91,79.39$, $77.75,76.86,70.81,69.71,69.04,66.81,64.31,27.87,26.36$, $24.35,20.90,20.76,20.66,18.08,17.33,14.54$. HRMS m/z calcd for $\mathrm{C}_{23} \mathrm{H}_{36} \mathrm{O}_{11} \mathrm{SNa}[\mathrm{M}+\mathrm{Na}]^{+}:$543.1876, found: 543.1862 .

\subsubsection{Ethyl 2,3,4-tri-O-acetyl- $\alpha-L-r h a m n o p y r a n o s y l-(1 \rightarrow 4)-2,3-$ $O$-isopropylidene- $\alpha$-L-rhamnopyranosyl- $(1 \rightarrow 4)-2,3-O$ -

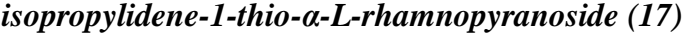

To a solution of $15(0.9 \mathrm{~g}, 1.7 \mathrm{mmol})$ in $\mathrm{MeOH}(15 \mathrm{~mL})$ was added $\mathrm{NaOMe}(30 \mathrm{mg})$. After stirring for $2 \mathrm{~h}$ at room temperature, the reaction mixture was neutralized with Dowex 50W $\left(\mathrm{H}^{+}\right)$, filtered and concentrated under reduced pressure. The residue was purified by flash chromatography $\left(\mathrm{CH}_{2} \mathrm{Cl}_{2}: \mathrm{CH}_{3} \mathrm{OH}\right.$, $30: 1)$ to give ethyl $\alpha$-L-rhamnopyranosyl- $(1 \rightarrow 4)-2,3-\mathrm{O}$ isopropylidene-1-thio- $\alpha$-L-rhamnopyranoside as white solid. Then, to the solution of the ethyl $\alpha$-L-rhamnopyranosyl- $(1 \rightarrow 4)$ 2,3-O-isopropylidene-1-thio- $\alpha$-L-rhamnopyranoside in 2,2dimethoxypropane $(10 \mathrm{~mL})$, $\mathrm{TsOH}^{\circ} \mathrm{H}_{2} \mathrm{O}(55 \mathrm{mg}, 0.29 \mathrm{mmol})$ was added and stirred for $2 \mathrm{~h}$ at $-10{ }^{\circ} \mathrm{C}$, the reaction was quenched with $\mathrm{Et}_{3} \mathrm{~N}(0.1 \mathrm{~mL})$ and then filtered and concentrated. The residue was applied to silica gel chromatography (petroleum ether-EtOAc, 6:1) to afford $\mathbf{1 6}$ as a syrup $(0.68 \mathrm{~g}, 90 \%)$.

To a suspension of 2,3,4-tri-O-acetyl - $\alpha$-L-rhamnopyranosyltri-chloroacetimidate $14(1.0 \mathrm{~g}, 2.3 \mathrm{mmol}), 16(0.50 \mathrm{~g}, 1.15$ mmol $)$ and $4 \AA \mathrm{MS}(1.0 \mathrm{~g})$ in dry $\mathrm{CH}_{2} \mathrm{Cl}_{2}(8 \mathrm{~mL})$ at $-78{ }^{\circ} \mathrm{C}$, was slowly added TMSOTf $(10 \mu \mathrm{L}, 0.06 \mathrm{mmol})$. After being stirred for $0.5 \mathrm{~h}$, the reaction was quenched with $\mathrm{Et}_{3} \mathrm{~N}(0.1 \mathrm{~mL})$ and then filtered and concentrated. The residue was purified by silica gel column chromatography (petroleum ether-EtOAc, 7:1) gave $\mathbf{1 7}$ $(0.67 \mathrm{~g}, 82 \%)$ as a white solid. ${ }^{1} \mathrm{H}$ NMR $\left(400 \mathrm{MHz}, \mathrm{CDCl}_{3}\right) \delta$ $5.60(\mathrm{~s}, 1 \mathrm{H}), 5.53(\mathrm{~s}, 1 \mathrm{H}), 5.35(\mathrm{br} \mathrm{s}, 1 \mathrm{H}), 5.30(\mathrm{~s}, 1 \mathrm{H}), 5.21(\mathrm{dd}$, $J=10.0,3.2 \mathrm{~Hz}, 1 \mathrm{H}), 5.07(\mathrm{t}, J=12.0 \mathrm{~Hz}, 1 \mathrm{H}), 4.22-4.13(\mathrm{~m}$, $4 \mathrm{H}), 4.06-3.99(\mathrm{~m}, 1 \mathrm{H}), 3.88(\mathrm{dq}, J=12.4,6.0 \mathrm{~Hz}, 1 \mathrm{H}), 3.72$ $(\mathrm{dq}, J=12.4,6.2 \mathrm{~Hz}, 1 \mathrm{H}), 3.63(\mathrm{dd}, J=9.8,7.6 \mathrm{~Hz}, 1 \mathrm{H}), 3.54$ (dd, $J=9.6,7.2 \mathrm{~Hz}, 1 \mathrm{H}), 2.67(\mathrm{dq}, J=14.4,7.2 \mathrm{~Hz}, 1 \mathrm{H}), 2.55$ $(\mathrm{dq}, J=14.8,7.4 \mathrm{~Hz}, 1 \mathrm{H}), 2.16(\mathrm{~s}, 3 \mathrm{H}), 2.06(\mathrm{~s}, 3 \mathrm{H}), 1.98(\mathrm{~m}$, $3 \mathrm{H}), 1.54(\mathrm{~d}, J=9.4 \mathrm{~Hz}, 6 \mathrm{H}), 1.35-1.27(\mathrm{~m}, 15 \mathrm{H}), 1.22(\mathrm{~d}, J$ $=6.2 \mathrm{~Hz}, 3 \mathrm{H}) .{ }^{13} \mathrm{C} \mathrm{NMR}\left(101 \mathrm{MHz}, \mathrm{CDCl}_{3}\right) \delta 169.94,169.91$, $169.80,130.77,128.63,109.36,109.23,95.72,95.38,79.22$, $78.10,77.77,76.76,76.23,70.67,69.53,68.97,66.62,64.36$, $64.06,27.78,27.68,26.29,26.14,24.19,20.75,20.61,20.53$, $17.88,17.63,17.19,14.43$. HRMS m/z calcd for $\mathrm{C}_{32} \mathrm{H}_{50} \mathrm{O}_{15} \mathrm{SNa}$ $[\mathrm{M}+\mathrm{Na}]^{+}:$729.2768, found: 729.2784

4.2.9 Ethyl 2,3,4-tri-O-acetyl- $\alpha$-L-rhamnopyranosyl-(1 $\rightarrow 4)-2,3-$ $O$-isopropylidene- $\alpha$-L-rhamnopyranosyl-(1 $\rightarrow 4)-2,3-O$ - isopropylidene

$(1 \rightarrow 4)-2,3-O$-isopropylidene- $\alpha-L$ rhamnopyranosyl-1-thio- $\alpha-L-r h a m n o p y r a n o s i d e(19)$

To a solution of $17(0.5 \mathrm{~g}, 0.7 \mathrm{mmol})$ in $\mathrm{CH}_{3} \mathrm{OH}(20 \mathrm{~mL})$ in was added $\mathrm{NaOMe}(30 \mathrm{mg})$. After stirring for $2 \mathrm{~h}$ at room temperature, the reaction mixture was neutralized with Dowex 50W $\left(\mathrm{H}^{+}\right)$, filtered and concentrated under reduced pressure. The residue was purified by flash chromatography (petroleum etherEtOAc, 8:1) to give Ethyl $\alpha$-L-rhamnopyranosyl-( $1 \rightarrow 4)-2,3-O$ isopropylidene- $\alpha$-L-rhamnopyranosyl- $(1 \rightarrow 4)-2,3-O$ -

isopropylidene

$(1 \rightarrow 4)-2,3-O$-isopropylidene- $\alpha-L$ rhamnopyranosyl-1-thio- $\alpha$-L-rhamnopyranoside as white solid. Then, to the solution of the ethyl $\alpha$-L-rhamnopyranosyl-( $1 \rightarrow 4)$ 2,3-O-isopropylidene-1-thio- $\alpha$-L-rhamnopyranoside in 2,2dimethoxypropane $(5 \mathrm{~mL})$, $\mathrm{TsOH} \cdot \mathrm{H}_{2} \mathrm{O}(30 \mathrm{mg}, 0.16 \mathrm{mmol})$ was added and stirred for $2 \mathrm{~h}$ at $-10{ }^{\circ} \mathrm{C}$, the reaction was quenched with $\mathrm{Et}_{3} \mathrm{~N}(0.1 \mathrm{~mL})$ and then filtered and concentrated. The residue was applied to silica gel chromatography (petroleum ether-EtOAc, 6:1) to afford $\mathbf{1 8}$ as white foam $(0.39 \mathrm{~g}, 88 \%)$.

To a suspension of 2,3,4-tri-O-acetyl - $\alpha$-L- rhamnopyranosyltri-chloroacetimidate $14(0.25 \mathrm{~g}, 0.58 \mathrm{mmol}), 18(0.30 \mathrm{~g}, 0.48$ mmol) and $4 \AA \mathrm{AS}(1.0 \mathrm{~g})$ in dry $\mathrm{CH}_{2} \mathrm{Cl}_{2}(8 \mathrm{~mL})$ at $-78^{\circ} \mathrm{C}$, was slowly added TMSOTf ( $18 \mu \mathrm{L}, 0.1 \mathrm{mmol})$. After being stirred for $2 \mathrm{~h}$, the reaction was quenched with $\mathrm{Et}_{3} \mathrm{~N}(0.1 \mathrm{~mL})$ and then filtered and concentrated. The residue was purified by silica gel column chromatography (petroleum ether-EtOAc, 8:1) gave 19 $(0.36 \mathrm{~g}, 83 \%)$ as a white solid. ${ }^{1} \mathrm{H}$ NMR $\left(400 \mathrm{MHz}, \mathrm{CDCl}_{3}\right) \delta$ $5.61(\mathrm{~s}, 2 \mathrm{H}), 5.52(\mathrm{~s}, 1 \mathrm{H}), 5.35(\mathrm{~s}, 1 \mathrm{H}), 5.31(\mathrm{~s}, 1 \mathrm{H}), 5.21(\mathrm{dd}$, $J=10.2,2.8 \mathrm{~Hz}, 1 \mathrm{H}), 5.07(\mathrm{t}, J=10.0 \mathrm{~Hz}, 1 \mathrm{H}), 4.31(\mathrm{t}, J=$ $6.6 \mathrm{~Hz}, 1 \mathrm{H}), 4.24-4.10(\mathrm{~m}, 6 \mathrm{H}), 4.01(\mathrm{dt}, J=12.0,6.0 \mathrm{~Hz}$, $1 \mathrm{H}), 3.87(\mathrm{dt}, J=12.8,6.4 \mathrm{~Hz}, 1 \mathrm{H}), 3.73-3.61(\mathrm{~m}, 3 \mathrm{H}), 3.53$ $(\mathrm{dd}, J=9.2,7.4 \mathrm{~Hz}, 1 \mathrm{H}), 2.66(\mathrm{dt}, J=14.4,7.2 \mathrm{~Hz}, 1 \mathrm{H}), 2.59$ -2.47 (m, 1H), 2.16 (s, 3H), 2.05 (s, 3H), 1.98 (s, 3H), 1.57 $1.51(\mathrm{~m}, 8 \mathrm{H}), 1.35-1.26(\mathrm{~m}, 21 \mathrm{H}), 1.21(\mathrm{~d}, J=6.0 \mathrm{~Hz}, 3 \mathrm{H})$, $0.96(\mathrm{t}, J=7.4 \mathrm{~Hz}, 1 \mathrm{H}) .{ }^{13} \mathrm{C} \mathrm{NMR}\left(101 \mathrm{MHz}, \mathrm{CDCl}_{3}\right) \delta$ $170.04,170.01,169.93,132.28,130.89,128.81,109.56$, 109.37, 109.34, 95.94, 95.67, 95.56, 79.46, 78.43, 78.31, 77.99, 76.93, 76.88, 76.48, 76.43, 76.39, 70.86, 69.70, 69.14, $66.80,64.59,64.43,64.19,30.54,27.97,27.91,26.48,26.32$, $24.39,20.94,20.80,20.71,18.00,17.81,17.36,14.62$. HRMS $\mathrm{m} / \mathrm{z}$ calcd for $\mathrm{C}_{41} \mathrm{H}_{64} \mathrm{O}_{19} \mathrm{SNa}[\mathrm{M}+\mathrm{Na}]^{+}$: 915.3660, found: 915.3646

\subsubsection{Diosgenyl 2,3,4-tri-O-acetyl-a-L-rhamnopyranosyl- $(1 \rightarrow 4)-2,3-O$-isopropylidene- $\alpha$-L-rhamnopyranosyl-( $1 \rightarrow 4)$ - [2,3,4-tri-O-benzoyl- $\alpha$-L-rhamnopyranosyl- $(1 \rightarrow 2)]-3,6-d i-O$ -

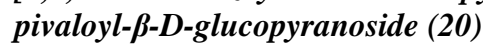

To a suspension of accept 9 (209 $\mathrm{mg}, 174 \mu \mathrm{mol})$, the thioglycoside donor 15 (181 mg, $348 \mu \mathrm{mol})$, and $4 \AA$ MS (250 $\mathrm{mg})$ in dry $\mathrm{CH}_{2} \mathrm{Cl}_{2}(10 \mathrm{~mL})$ at $-10{ }^{\circ} \mathrm{C}$, was added NIS $(78 \mathrm{mg}$, $347 \mu \mathrm{mol})$ and AgOTf (13 mg, $51 \mu \mathrm{mol})$. After being stirred for $0.5 \mathrm{~h}$ at this temperature, the reaction was quenched with $\mathrm{Et}_{3} \mathrm{~N}$ $(0.1 \mathrm{~mL})$, and then filtered and concentrated. The products were isolated by silica gel column chromatography $(3: 1$, petroleum ether-EtOAc) to give $20(250 \mathrm{mg}, 87 \%)$ as white foam. $[\alpha]_{\mathrm{D}}$ $42.5^{\circ}\left(c 1.0, \mathrm{CHCl}_{3}\right) ;{ }^{1} \mathrm{H}$ NMR $\left(400 \mathrm{MHz}, \mathrm{CDCl}_{3}\right) \delta 7.98(\mathrm{~d}, J$ $=7.6 \mathrm{~Hz}, 2 \mathrm{H}), 7.85(\mathrm{~d}, J=7.6 \mathrm{~Hz}, 2 \mathrm{H}), 7.71(\mathrm{~d}, J=7.6 \mathrm{~Hz}$, $2 \mathrm{H}), 7.53(\mathrm{t}, J=7.2 \mathrm{~Hz}, 1 \mathrm{H}), 7.43(\mathrm{dd}, J=13.8,5.4 \mathrm{~Hz}, 3 \mathrm{H})$, $7.32(\mathrm{~d}, J=7.3 \mathrm{~Hz}, 1 \mathrm{H}), 7.25(\mathrm{t}, J=7.6 \mathrm{~Hz}, 2 \mathrm{H}), 7.16(\mathrm{t}, J=$ $7.6 \mathrm{~Hz}, 2 \mathrm{H}), 5.72-5.64(\mathrm{~m}, 1 \mathrm{H}), 5.57-5.49(\mathrm{~m}, 2 \mathrm{H}), 5.37$ $(\mathrm{d}, J=8.6 \mathrm{~Hz}, 2 \mathrm{H}), 5.21(\mathrm{~d}, J=10.7 \mathrm{~Hz}, 2 \mathrm{H}), 5.14-4.95(\mathrm{~m}$, $5 \mathrm{H}), 4.65(\mathrm{dd}, J=14.4,6.8 \mathrm{~Hz}, 2 \mathrm{H}), 4.40-4.33(\mathrm{~m}, 1 \mathrm{H}), 4.29$ $-4.17(\mathrm{~m}, 3 \mathrm{H}), 4.11-4.06(\mathrm{~m}, 1 \mathrm{H}), 3.99(\mathrm{t}, J=6.6 \mathrm{~Hz}, 3 \mathrm{H})$, $3.86(\mathrm{~d}, J=5.4 \mathrm{~Hz}, 1 \mathrm{H}), 3.80(\mathrm{~s}, 2 \mathrm{H}), 3.76-3.64(\mathrm{~m}, 3 \mathrm{H})$, 
$3.58(\mathrm{~s}, 1 \mathrm{H}), 3.39(\mathrm{t}, J=8.6 \mathrm{~Hz}, 2 \mathrm{H}), 3.30(\mathrm{~d}, J=11.2 \mathrm{~Hz}$, $1 \mathrm{H}), 2.49(\mathrm{~d}, J=11.0 \mathrm{~Hz}, 1 \mathrm{H}), 2.32(\mathrm{t}, J=11.8 \mathrm{~Hz}, 1 \mathrm{H}), 2.07$ $(\mathrm{s}, 3 \mathrm{H}), 1.97(\mathrm{~s}, 6 \mathrm{H}), 1.87(\mathrm{~s}, 3 \mathrm{H}), 1.54(\mathrm{dt}, J=14.2,7.0 \mathrm{~Hz}$, $8 \mathrm{H}), 1.42(\mathrm{~s}, 5 \mathrm{H}), 1.25(\mathrm{~s}, 5 \mathrm{H}), 1.17(\mathrm{~d}, J=8.0 \mathrm{~Hz}, 17 \mathrm{H}), 1.09$ $(\mathrm{s}, 9 \mathrm{H}), 0.90-0.85(\mathrm{~m}, 9 \mathrm{H}), 0.72(\mathrm{~d}, J=7.8 \mathrm{~Hz}, 6 \mathrm{H}) \cdot{ }^{13} \mathrm{C}$ NMR $\left(101 \mathrm{MHz}, \mathrm{CDCl}_{3}\right) \delta 178.03,176.85,171.31,170.06$, $170.01,169.90,167.77,165.73,165.33,165.11,140.10$, $133.40,133.27,132.98,132.37,130.97,129.91,129.85$, $129.75,129.49,129.37,128.89,128.60,128.40,128.23$, $122.19,109.69,109.34,99.57,97.60,96.21,96.10,80.86$, 79.53, 77.69, 77.30, 76.27, 76.01, 75.79, 74.81, 72.29, 71.89, $70.92,70.44,69.92,69.80,69.11,66.97,66.91,65.62,64.41$, 62.17, 56.48, 50.09, 41.67, 40.33, 38.93, 36.89, 32.19, 31.95, $31.54,31.47,30.69,30.63,30.36,29.93,29.75,28.87,27.84$, $27.26,27.07,26.27,21.07,21.01,20.89,20.73,19.30,19.24$, $19.18,17.98,17.53,17.48,17.21,16.34,14.60,13.79,13.76$. HRMS m/z calcd for $\mathrm{C}_{91} \mathrm{H}_{120} \mathrm{O}_{28} \mathrm{Na}[\mathrm{M}+\mathrm{Na}]^{+}: 1683.7864$, found: 1683.7833

4.2.11 Diosgenyl 2,3,4-tri-O-acetyl- $\alpha$-L-rhamnopyranosyl$(1 \rightarrow 4)-2,3-O$-isopropylidene- $\alpha-L-r h a m n o p y r a n o s y l-(1 \rightarrow 4)-2,3-$ $O$-isopropylidene- $\alpha$-L-rhamnopyranosyl- $(1 \rightarrow 4)[2,3,4-$ tri-O-

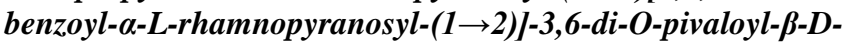
glucopyranoside (21)

To a suspension of accept $9(80 \mathrm{mg}, 67 \mu \mathrm{mol})$, the thioglycoside donor 17 (57 mg, $80 \mu \mathrm{mol})$, and $4 \AA \mathrm{MS}(100 \mathrm{mg})$ in dry $\mathrm{CH}_{2} \mathrm{Cl}_{2}(5 \mathrm{~mL})$ at $-10{ }^{\circ} \mathrm{C}$, was added NIS $(18 \mathrm{mg}, 80 \mu \mathrm{mol})$ and $\operatorname{AgOTf}(7 \mathrm{mg}, 27 \mu \mathrm{mol})$. After being stirred for $0.5 \mathrm{~h}$ at this temperature, the reaction was quenched with $\mathrm{Et}_{3} \mathrm{~N}(0.1 \mathrm{~mL})$, and then filtered and concentrated. Chromatography $(3: 1$, petroleum ether-EtOAc) to give 21 (63 mg, 51\%) as white foam. ${ }^{1} \mathrm{H}$ NMR $\left(400 \mathrm{MHz}, \mathrm{CDCl}_{3}\right) \delta 8.05(\mathrm{~d}, J=7.4 \mathrm{~Hz}, 2 \mathrm{H}), 7.92(\mathrm{~d}, J=7.4$ $\mathrm{Hz}, 2 \mathrm{H}), 7.78(\mathrm{~d}, J=7.6 \mathrm{~Hz}, 2 \mathrm{H}), 7.73-7.71(\mathrm{~m}, 1 \mathrm{H}), 7.61$ $(\mathrm{t}, J=6.2 \mathrm{~Hz}, 1 \mathrm{H}), 7.53-7.50(\mathrm{~m}, 2 \mathrm{H}), 7.40(\mathrm{~d}, J=7.0 \mathrm{~Hz}$, $1 \mathrm{H}), 7.32(\mathrm{t}, J=7.8 \mathrm{~Hz}, 2 \mathrm{H}), 7.24(\mathrm{t}, J=7.6 \mathrm{~Hz}, 2 \mathrm{H}), 5.76$ $(\mathrm{dd}, J=10.1,3.2 \mathrm{~Hz}, 1 \mathrm{H}), 5.63(\mathrm{~s}, 1 \mathrm{H}), 5.61(\mathrm{~d}, J=3.8 \mathrm{~Hz}$, $1 \mathrm{H}), 5.58(\mathrm{~d}, J=3.4 \mathrm{~Hz}, 1 \mathrm{H}), 5.45-5.37(\mathrm{~m}, 3 \mathrm{H}), 5.34(\mathrm{~s}$, $2 \mathrm{H}), 5.31(\mathrm{~d}, J=2.1 \mathrm{~Hz}, 1 \mathrm{H}), 5.21(\mathrm{dd}, J=10.1,3.4 \mathrm{~Hz}, 2 \mathrm{H})$, $5.17(\mathrm{~s}, 1 \mathrm{H}), 5.13(\mathrm{~s}, 1 \mathrm{H}), 5.07(\mathrm{td}, J=9.6,3.0 \mathrm{~Hz}, 2 \mathrm{H}), 4.75$ $-4.68(\mathrm{~m}, 2 \mathrm{H}), 4.31(\mathrm{t}, J=6.6 \mathrm{~Hz}, 3 \mathrm{H}), 4.19(\mathrm{dd}, J=11.4$, $6.0 \mathrm{~Hz}, 2 \mathrm{H}), 4.15-4.05(\mathrm{~m}, 4 \mathrm{H}), 3.98-3.94(\mathrm{~m}, 1 \mathrm{H}), 3.86-$ $3.69(\mathrm{~m}, 5 \mathrm{H}), 3.52(\mathrm{dd}, J=8.8,6.4 \mathrm{~Hz}, 4 \mathrm{H}), 3.37(\mathrm{~d}, J=10.8$ $\mathrm{Hz}, 1 \mathrm{H}), 2.55(\mathrm{~d}, J=13.2 \mathrm{~Hz}, 1 \mathrm{H}), 2.37(\mathrm{~d}, J=12.0 \mathrm{~Hz}, 1 \mathrm{H})$, $2.16(\mathrm{~d}, J=1.4 \mathrm{~Hz}, 6 \mathrm{H}), 2.05(\mathrm{~s}, 6 \mathrm{H}), 1.98(\mathrm{~s}, 6 \mathrm{H}), 1.72(\mathrm{~d}, J$ $=2.2 \mathrm{~Hz}, 3 \mathrm{H}), 1.51(\mathrm{~d}, J=6.6 \mathrm{~Hz}, 8 \mathrm{H}), 1.34(\mathrm{~s}, 9 \mathrm{H}), 1.24(\mathrm{t}, J$ $=4.1 \mathrm{~Hz}, 14 \mathrm{H}), 1.17(\mathrm{~s}, 9 \mathrm{H}), 0.99-0.92(\mathrm{~m}, 12 \mathrm{H}), 0.79(\mathrm{~d}, J$ $=8.1 \mathrm{~Hz}, 6 \mathrm{H}) .{ }^{13} \mathrm{C} \mathrm{NMR}\left(101 \mathrm{MHz}, \mathrm{CDCl}_{3}\right) \delta 178.04,176.84$, $170.01,167.72,165.67,165.32,165.08,140.06,133.39$, $132.31,130.92,129.86,129.78,129.71,129.38,129.26$, $128.84,128.57,128.35,128.19,122.12,109.56,109.35$, 109.29, 95.94, 95.52, 80.81, 79.46, 77.93, 77.25, 76.40, 76.23, 75.90, 75.30, 74.31, 74.03, 72.48, 72.07, 71.81, 70.96, 70.36, $69.93,69.73,69.13,66.81,65.57,64.28,62.11,56.43,53.44$, 50.03, 41.62, 40.27, 39.71, 38.85, 37.16, 36.84, 32.13, 31.49, $30.57,30.30,29.88,29.70,27.87,27.83,27.22,27.18,27.15$, $27.02,26.29,26.24,20.98,20.83,20.74,19.25,19.19,17.84$, 17.47, 17.39, 17.15, 16.29, 14.55, 13.74. HRMS m/z calcd for $\mathrm{C}_{100} \mathrm{H}_{134} \mathrm{O}_{32} \mathrm{Na}[\mathrm{M}+\mathrm{Na}]^{+}: 1869.8756$, found: 1869.8723 .

4.2.12 Diosgenyl 2,3,4-tri-O-acetyl-a-L-rhamnopyranosyl$(1 \rightarrow 4)-2,3-O$-isopropylidene- $\alpha-L$-rhamnopyranosyl-( $1 \rightarrow 4)-2,3$ O-isopropylidene- $\alpha$-L-rhamnopyranosyl- $(1 \rightarrow 4)-2,3-O$ isopropylidene- $\alpha$-L-rhamnopyranosyl-( $1 \rightarrow 4)$-[2,3,4-tri-O-

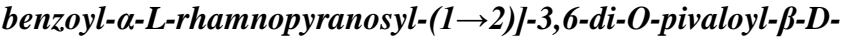
glucopyranoside (22)
To a suspension of accept $9(100 \mathrm{mg}, 83 \mu \mathrm{mol})$, the thioglycoside donor $17(89 \mathrm{mg}, 100 \mu \mathrm{mol})$, and $4 \AA$ MS (100 mg) in dry $\mathrm{CH}_{2} \mathrm{Cl}_{2}(5 \mathrm{~mL})$ at $-10{ }^{\circ} \mathrm{C}$, was added NIS $(22 \mathrm{mg}, 98 \mu \mathrm{mol})$ and $\operatorname{AgOTf}(9 \mathrm{mg}, 33 \mu \mathrm{mol})$. After being stirred for $0.5 \mathrm{~h}$ at this temperature, the reaction was quenched with $\mathrm{Et}_{3} \mathrm{~N}(0.1 \mathrm{~mL})$, and then filtered and concentrated. Chromatography (3:1, petroleum ether-EtOAc) afforded the compound $22(93 \mathrm{mg}, 60 \%)$ as white foam. ${ }^{1} \mathrm{H} \mathrm{NMR}\left(400 \mathrm{MHz}, \mathrm{CDCl}_{3}\right) \delta 8.06(\mathrm{~d}, J=7.4 \mathrm{~Hz}, 2 \mathrm{H})$, $7.92(\mathrm{~d}, J=7.4 \mathrm{~Hz}, 1 \mathrm{H}), 7.78(\mathrm{~d}, J=7.4 \mathrm{~Hz}, 2 \mathrm{H}), 7.71(\mathrm{dt}, J=$ 7.2, $3.6 \mathrm{~Hz}, 1 \mathrm{H}), 7.62(\mathrm{dd}, J=13.8,7.2 \mathrm{~Hz}, 1 \mathrm{H}), 7.54-7.47$ (m, 4H), $7.40(\mathrm{~d}, J=7.0 \mathrm{~Hz}, 1 \mathrm{H}), 7.32(\mathrm{~d}, J=7.8 \mathrm{~Hz}, 1 \mathrm{H})$, $7.24(\mathrm{t}, J=7.4 \mathrm{~Hz}, 2 \mathrm{H}), 5.76(\mathrm{dd}, J=10.0,3.2 \mathrm{~Hz}, 1 \mathrm{H}), 5.65$ $-5.56(\mathrm{~m}, 4 \mathrm{H}), 5.46-5.29(\mathrm{~m}, 5 \mathrm{H}), 5.24-5.16(\mathrm{~m}, 2 \mathrm{H}), 5.09$ (dd, $J=19.6,9.6 \mathrm{~Hz}, 2 \mathrm{H}), 4.77-4.67(\mathrm{~m}, 1 \mathrm{H}), 4.47-4.35$ $(\mathrm{m}, 2 \mathrm{H}), 4.30(\mathrm{dd}, J=11.9,5.2 \mathrm{~Hz}, 3 \mathrm{H}), 4.22(\mathrm{dt}, J=10.5$, $3.8 \mathrm{~Hz}, 2 \mathrm{H}), 4.17-4.08(\mathrm{~m}, 4 \mathrm{H}), 4.00-3.95(\mathrm{~m}, 1 \mathrm{H}), 3.92-$ $3.46(\mathrm{~m}, 12 \mathrm{H}), 3.39(\mathrm{t}, J=10.8 \mathrm{~Hz}, 1 \mathrm{H}), 2.56(\mathrm{~d}, J=13.0 \mathrm{~Hz}$, $1 \mathrm{H}), 2.39$ (t, $J=11.6 \mathrm{~Hz}, 1 \mathrm{H}), 2.16(\mathrm{~s}, 3 \mathrm{H}), 2.05(\mathrm{~s}, 3 \mathrm{H}), 1.98$ $(\mathrm{s}, 4 \mathrm{H}), 1.80(\mathrm{~d}, J=6.4 \mathrm{~Hz}, 2 \mathrm{H}), 1.72(\mathrm{dt}, J=14.7,6.8 \mathrm{~Hz}$, 4H), 1.60 (s, 4H), 1.53 (s, 9H), $1.47-1.40(\mathrm{~m}, 5 \mathrm{H}), 1.33$ (d, $J$ $=5.8 \mathrm{~Hz}, 8 \mathrm{H}), 1.30-1.19(\mathrm{~m}, 30 \mathrm{H}), 1.17(\mathrm{~s}, 6 \mathrm{H}), 0.99-0.94$ $(\mathrm{m}, 8 \mathrm{H}), 0.79(\mathrm{~d}, J=6.8 \mathrm{~Hz}, 5 \mathrm{H}) .{ }^{13} \mathrm{C}$ NMR $(101 \mathrm{MHz}$, $\left.\mathrm{CDCl}_{3}\right) \delta 178.06,176.85,170.05,169.99,167.72,165.67$, $165.35,165.08,140.06,133.41,132.98,132.30,130.92$, $129.94,129.86,129.78,129.70,129.37,129.29,129.22$, $128.84,128.56,128.46,128.35,128.20,122.12,109.88$, $109.60,109.38,109.29,99.33,97.25,96.44,95.95,95.56$, 80.80, 79.44, 78.36, 78.12, 78.00, 77.38, 77.26, 77.06, 76.88, $76.75,76.41,76.25,75.84,75.45,74.39,72.63,71.79,70.91$, $70.35,69.95,69.73,69.17,66.81,65.56,64.43,64.17,63.67$, $62.11,56.42,50.03,41.61,40.27,39.70,38.85,38.72,37.16$, $36.84,32.12$, 31.89, 31.48, 31.40, 30.56, 30.29, 30.19, 29.88, $29.69,28.80,28.59,27.89,27.85,27.20,27.02,26.53,26.35$, 20.97, 20.83, 20.74, 19.25, 19.18, 17.83, 17.73, 17.47, 17.39, $17.15,16.28,14.55,13.73$. HRMS m/z calcd for $\mathrm{C}_{109} \mathrm{H}_{147} \mathrm{O}_{36}$ [M-H] : 2031.9672, found: 2031.9677.

\section{Typical procedure for deprotecting of compounds 20-22}

A fully protected saponin $\mathbf{2 0 - 2 2}(100 \mathrm{mg})$ was dissolved in $80 \% \mathrm{HOAc}$ and the solution was stirred at $80{ }^{\circ} \mathrm{C}$ for $5 \mathrm{~h}$ to remove isopropylidene protecting group. Then the solvent was evaporated to get a residue. The above residue was dissolved in THF-CH $\mathrm{CH}_{3} \mathrm{OH}-\mathrm{H}_{2} \mathrm{O}(9 \mathrm{~mL}, \mathrm{v} / \mathrm{v} / \mathrm{v}=1: 1: 1) . \mathrm{NaOH}(40 \mathrm{mg})$ was added and the mixture was stirred at $45{ }^{\circ} \mathrm{C}$ for $18 \mathrm{~h}$ to remove other protecting groups. The solution was neutralized with Dowex-50 $\left(\mathrm{H}^{+}\right)$resin, filtered, and concentrated. The residue was purified by silica gel column chromatography $\left(\mathrm{CH}_{2} \mathrm{Cl}_{2}: \mathrm{CH}_{3} \mathrm{OH}\right.$ 10:1-3:1) to afford target compounds 4-6.

\subsubsection{Diosgenyl $\alpha$-L-rhamnopyranosyl-( $1 \rightarrow 4)-\alpha-L$ -

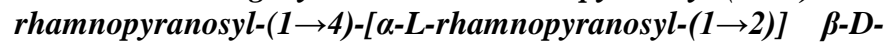 glucopyranoside (4)}

Purification by silica gel column chromatography $\left(\mathrm{CH}_{2} \mathrm{Cl}_{2}\right.$ : $\left.\mathrm{CH}_{3} \mathrm{OH}, 4: 1\right)$ gave a white solid (56 mg, 93\%): $R_{f} 0.38(4: 1$ $\left.\mathrm{CH}_{2} \mathrm{Cl}_{2}-\mathrm{CH}_{3} \mathrm{OH}\right) ; \quad[\alpha]_{\mathrm{D}} 105^{\circ}(c \quad 0.5, \mathrm{MeOH}){ }^{1} \mathrm{H}$ NMR $(400$ $\left.\mathrm{MHz}, \mathrm{CD}_{3} \mathrm{OD} / \mathrm{CDCl}_{3}\right) \delta 5.37(\mathrm{~s}, 1 \mathrm{H}), 5.18(\mathrm{~d}, J=7.5 \mathrm{~Hz}, 2 \mathrm{H})$, $4.54(\mathrm{~s}, 1 \mathrm{H}), 4.48(\mathrm{~d}, J=7.7 \mathrm{~Hz}, 1 \mathrm{H}), 4.39(\mathrm{dd}, J=14.7,7.2$ $\mathrm{Hz}, 1 \mathrm{H}), 4.10(\mathrm{dt}, J=12.2,6.1 \mathrm{~Hz}, 1 \mathrm{H}), 4.01(\mathrm{dt}, J=12.5,6.3$ $\mathrm{Hz}, 1 \mathrm{H}), 3.94(\mathrm{~s}, 2 \mathrm{H}), 3.82-3.74(\mathrm{~m}, 3 \mathrm{H}), 3.72-3.50(\mathrm{~m}$, 9H), $3.48-3.34(\mathrm{~m}, 5 \mathrm{H}), 2.43(\mathrm{~d}, J=10.2 \mathrm{~Hz}, 1 \mathrm{H}), 2.28(\mathrm{t}, J$ $=11.7 \mathrm{~Hz}, 1 \mathrm{H}), 2.04-1.82(\mathrm{~m}, 6 \mathrm{H}), 1.80-1.71(\mathrm{~m}, 2 \mathrm{H})$, $1.69-1.36(\mathrm{~m}, 11 \mathrm{H}), 1.33-1.21(\mathrm{~m}, 14 \mathrm{H}), 1.14(\mathrm{ddd}, J=$ 28.6, 17.2, 7.6 Hz, 3H), 1.03 (s, 3H), $0.99-0.84(\mathrm{~m}, 6 \mathrm{H})$, $0.79(\mathrm{~d}, J=7.0 \mathrm{~Hz}, 6 \mathrm{H}) .{ }^{13} \mathrm{C}$ NMR $\left(101 \mathrm{MHz}, \mathrm{MeOD} / \mathrm{CDCl}_{3}\right) \delta$ 
139.90, 120.84, 108.80, 101.17, 100.76, 100.35, 98.60, 80.34, 78.91, 77.86, 77.47, 76.05, 74.67, 72.03, 71.91, 70.96, 70.46, $70.17,68.51,67.85,67.27,66.04,61.67,60.04,59.99,55.91$, 52.87, 49.71, 41.00, 39.56, 39.05, 37.62, 36.65, 36.16, 31.34, $30.87,30.55,29.53,28.85,27.97,20.12,18.12,16.80,16.24$, 16.12, 15.81, 15.11, 13.19. HRMS m/z calcd for $\mathrm{C}_{51} \mathrm{H}_{82} \mathrm{O}_{20} \mathrm{Na}$ $[\mathrm{M}+\mathrm{Na}]^{+}: 1037.5297$, found: 1037.5290 .

\subsubsection{Diosgenyl $\alpha$-L-rhamnopyranosyl- $(1 \rightarrow 4)-\alpha-L$ -

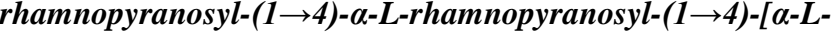

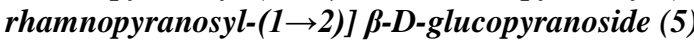

Purification by silica gel column chromatography $\left(\mathrm{CH}_{2} \mathrm{Cl}_{2}\right.$ : $\left.\mathrm{CH}_{3} \mathrm{OH}, 4: 1\right)$ gave a white solid $(56 \mathrm{mg}, 90 \%): R_{f} 0.30$ (4:1 $\left.\mathrm{CH}_{2} \mathrm{Cl}_{2}-\mathrm{CH}_{3} \mathrm{OH}\right) ;[\alpha]_{\mathrm{D}}+103^{\circ}\left(c 0.52, \mathrm{CH}_{3} \mathrm{OH}\right) ;{ }^{1} \mathrm{H}$ NMR $(400$ MHz, d-DMSO) $\delta 5.31(\mathrm{~s}, 1 \mathrm{H}), 5.05(\mathrm{~s}, 2 \mathrm{H}), 5.02(\mathrm{~d}, J=4.8$ $\mathrm{Hz}, 1 \mathrm{H}), 5.00(\mathrm{~s}, 1 \mathrm{H}), 4.92-4.86(\mathrm{~m}, 2 \mathrm{H}), 4.83-4.55(\mathrm{~m}$, $11 \mathrm{H}), 4.37(\mathrm{~d}, J=7.3 \mathrm{~Hz}, 1 \mathrm{H}), 4.26(\mathrm{~d}, J=7.2 \mathrm{~Hz}, 1 \mathrm{H}), 4.02$ - $3.88(\mathrm{~m}, 1 \mathrm{H}), 3.70(\mathrm{~s}, 3 \mathrm{H}), 3.64-3.47(\mathrm{~m}, 8 \mathrm{H}), 3.18(\mathrm{dd}, J$ $=12.0,6.7 \mathrm{~Hz}, 5 \mathrm{H}), 2.39(\mathrm{~d}, J=8.6 \mathrm{~Hz}, 1 \mathrm{H}), 2.13(\mathrm{dd}, J=$ 24.2, $11.7 \mathrm{~Hz}, 1 \mathrm{H}), 1.90(\mathrm{~s}, 2 \mathrm{H}), 1.82-1.73(\mathrm{~m}, 3 \mathrm{H}), 1.66(\mathrm{~s}$, $2 \mathrm{H}), 1.50(\mathrm{dt}, J=38.0,12.4 \mathrm{~Hz}, 8 \mathrm{H}), 1.31-1.20(\mathrm{~m}, 5 \mathrm{H})$, $1.11(\mathrm{dt}, J=17.3,8.7 \mathrm{~Hz}, 18 \mathrm{H}), 0.90(\mathrm{dd}, J=21.1,14.4 \mathrm{~Hz}$, $9 \mathrm{H}), 0.72(\mathrm{~d}, J=4.0 \mathrm{~Hz}, 6 \mathrm{H}) .{ }^{13} \mathrm{C}$ NMR $(101 \mathrm{MHz}, \mathrm{d}-\mathrm{DMSO})$ $\delta 140.41,121.42,108.55,101.15,100.45,100.15,98.34$, $93.88,80.32,79.02,78.66,78.07,77.98,77.84,76.67,76.36$, $76.12,76.00,75.45,72.08,71.60,71.21,70.87,70.71,70.47$, $69.03,68.04,67.27,66.75,66.03,61.90,55.87,49.68,41.21$, $40.23,40.02,39.81,39.60,39.39,39.18,38.97,37.70,36.93$, $36.52,31.64,31.10,29.94,29.13,28.60,20.50,19.10,18.55$, 18.28, 17.93, 17.22, 16.15, 14.80. HRMS m/z calcd for $\mathrm{C}_{57} \mathrm{H}_{92} \mathrm{O}_{24} \mathrm{Na}[\mathrm{M}+\mathrm{Na}]^{+}:$1183.5876, found: 1183.5823 .

\subsubsection{Diosgenyl a-L-rhamnopyranosyl-(1 $\rightarrow 4)-\alpha-L$ -

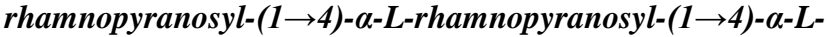 rhamnopyranosyl-( $1 \rightarrow 4)$-[ $\alpha$-L-rhamnopyranosyl- $(1 \rightarrow 2)]-\beta$ - $D$ - glucopyranoside (6)}

Purification by silica gel column chromatography (DCM: $\mathrm{MeOH}, 4: 1)$ gave a white solid (57 mg, 88\%): $R_{f} 0.26(3: 1$ $\left.\mathrm{CH}_{2} \mathrm{Cl}_{2}-\mathrm{CH}_{3} \mathrm{OH}\right) ; \quad[\alpha]_{\mathrm{D}}+101^{\circ}\left(c 0.16, \mathrm{CH}_{3} \mathrm{OH}\right){ }^{1} \mathrm{H}$ NMR (400 $\left.\mathrm{MHz}, \mathrm{CD}_{3} \mathrm{OD} / \mathrm{CDCl}_{3}\right) \delta 5.33(\mathrm{~s}, 1 \mathrm{H}), 5.13(\mathrm{~s}, 2 \mathrm{H}), 5.09(\mathrm{~s}$, $\left.1 \mathrm{H}, \mathrm{H}-1^{\mathrm{r}^{\prime \prime \prime \prime}\left(\mathrm{g}^{\prime}\right)}\right), 5.08\left(\mathrm{~s}, 1 \mathrm{H}, \mathrm{H}-1^{\mathrm{r}^{\prime \prime \prime \prime}}\left(\mathrm{g}^{\prime}\right)\right), 4.44(\mathrm{~d}, J=7.8 \mathrm{~Hz}, 1 \mathrm{H})$, $4.36(\mathrm{dd}, J=15.0,7.2 \mathrm{~Hz}, 1 \mathrm{H}), 4.11-4.04(\mathrm{~m}, 1 \mathrm{H}), 3.99$ (dd, $J=9.2,6.2 \mathrm{~Hz}, 1 \mathrm{H}), 3.92(\mathrm{~d}, J=8.6 \mathrm{~Hz}, 2 \mathrm{H}), 3.87(\mathrm{~s}, 2 \mathrm{H})$, $3.76(\mathrm{~d}, J=10.4 \mathrm{~Hz}, 2 \mathrm{H}), 3.73-3.65(\mathrm{~m}, 6 \mathrm{H}), 3.61(\mathrm{dd}, J=$ 10.0, $2.4 \mathrm{~Hz}, 2 \mathrm{H}), 3.56-3.46(\mathrm{~m}, 6 \mathrm{H}), 3.40-3.33(\mathrm{~m}, 3 \mathrm{H})$, $3.32(\mathrm{~s}, 1 \mathrm{H}), 3.28(\mathrm{dd}, J=3.0,1.6 \mathrm{~Hz}, 5 \mathrm{H}), 2.39(\mathrm{~d}, J=10.4$ $\mathrm{Hz}, 1 \mathrm{H}), 2.25(\mathrm{t}, J=12.4 \mathrm{~Hz}, 1 \mathrm{H}), 1.95(\mathrm{dd}, J=11.0,6.4 \mathrm{~Hz}$, $2 \mathrm{H}), 1.89-1.80(\mathrm{~m}, 3 \mathrm{H}), 1.71(\mathrm{dd}, J=9.2,5.8 \mathrm{~Hz}, 2 \mathrm{H}), 1.64$ $-1.46(\mathrm{~m}, 9 \mathrm{H}), 1.44-1.36(\mathrm{~m}, 2 \mathrm{H}), 1.33-1.17(\mathrm{~m}, 25 \mathrm{H})$, $1.16-1.09(\mathrm{~m}, 2 \mathrm{H}), 1.04-0.98(\mathrm{~m}, 4 \mathrm{H}), 0.92(\mathrm{q}, J=9.6 \mathrm{~Hz}$, $5 \mathrm{H}), 0.83(\mathrm{dd}, J=11.2,4.4 \mathrm{~Hz}, 2 \mathrm{H}), 0.75(\mathrm{~d}, J=6.8 \mathrm{~Hz}, 6 \mathrm{H})$. ${ }^{13} \mathrm{C}$ NMR (101 MHz, $\left.\mathrm{CD}_{3} \mathrm{OD} / \mathrm{CDCl}_{3}\right) \delta 170.12,141.35$, $122.28,110.23,102.72,102.64,102.61,102.14,101.82$, $100.08,81.77,81.00,80.54,79.22,79.01,78.87,78.69,78.36$, $77.50,76.13,73.48,73.40,72.58,72.48,72.28,71.85,71.61$, $69.94,69.32,68.69,68.46,67.49,63.12,61.48,57.35,51.15$, $49.65,49.44,49.23,49.01,48.80,48.59,48.37,48.16,42.45$, $41.01,40.49,39.07,38.09,37.61,32.78,32.63,32.31,32.00$, $30.97,30.30,29.42,23.32,21.57,19.57,18.26,17.70,17.57$, 17.25, 16.56, 14.64. HRMS $\mathrm{m} / \mathrm{z}$ calcd for $\mathrm{C}_{63} \mathrm{H}_{102} \mathrm{O}_{28} \mathrm{Na}$ $[\mathrm{M}+\mathrm{Na}]^{+}:$1329.6450, found: 1329.6279 .

\subsection{Cytotoxicity test}

The human hepatocellular carcinoma cell lines (HepG2) and human normal liver cells L02 were purchased from Shanghai Institutes for Biological Sciences, Chinese Academy of Sciences (Shanghai, China) and were maintained in Dulbecco's modified Eagle's medium. A total of 8000 cells in the logarithmic phase/well were seeded on 96-well plates with supplemented culture medium $(100 \mu \mathrm{L} /$ well $)$ and incubated at $37{ }^{\circ} \mathrm{C}$ in a humidified atmosphere containing $5 \% \mathrm{CO}_{2}$ for $24 \mathrm{~h}$. Cultured medium was removed and replaced with serum free supplemented medium (100 $\mu \mathrm{L} /$ well $)$. After the cells were incubated with different concentrations of saponins 1-7 for $24 \mathrm{~h}$, MTT $(0.5 \mathrm{mg} / \mathrm{mL})$ was diluted in phosphate-buffered saline (PBS) and added to each well with a further incubation for $4 \mathrm{~h}$. All cytotoxicity tests were run parallel with a set of negative controls: cells without addition of complex for comparison. Finally, the cells were dissolved with $100 \mu \mathrm{L}$ of dimethyl sulfoxide (DMSO) and then analyzed in a multiwall plate reader at $570 \mathrm{~nm}$ (BioTek Instruments, Inc.)

\section{Declaration of competing interest}

The authors declare that they have no known competing financial interests or personal relationships that could have appeared to influence the work reported in this paper.

\section{Acknowledgments}

This work was financially supported by the Natural Science Foundation of China, China $(21502139,21702123)$ and International Science \& Technology Cooperation Program of China (2013DFA31160).

\section{Appendix A. Supplementary data}

Supplementary data to this article can be found online at https://doi.org/10.1016/XXXXX

\section{References}

1. L. Si, L. Zheng, L. Xu, L. Yin, X. Han, Y. Qi, Y. Xu, C. Wang, J. Peng, Dioscin suppresses human laryngeal cancer cells growth via induction of cell-cycle arrest and MAPK-mediated mitochondrialderived apoptosis and inhibition of tumor invasion, Eur. J. Pharmacol. 774 (2016) 105-117

2. Z. Chen, J. Xu, Y. Wu, S. Lei, H. Liu, Q. Meng, Z. Xia, Diosgenin inhibited the expression of TAZ in hepatocellular carcinoma, Biochem. Biophys. Res. Commun. 503 (2018) 1181-1185.

3. X. Meng, H. Dong, Y. Pan, L. Ma, C. Liu, S. Man, W. Gao, Diosgenyl Saponin inducing endoplasmic reticulum stress and mitochondriamediated apoptotic pathways in liver Cancer cells, J. Agric. Food Chem. 67 (2019) 11428-11435.

4. P.R. Ravikumar, P. Hammesfahr, C.J. Sih, Cytotoxic saponins from the Chinese herbal drug Yunnan Bai Yao. J Pharm Sci. 68 (1979) 900-903.

5. C. Li, B. Yu, M. Liu, Y. Hui. Synthesis of diosgenyl $\alpha-1-$ rhamnopyranosyl- $(1 \rightarrow 2)$-[ $\beta$-d-glucopyranosyl- $(1 \rightarrow 3)]-\beta$-d-

glucopyranoside (gracillin) and related saponins. Carbohydr. Res. 306 (1998) 189-195

6. Y. Wang, Y. Zhang, B. Yu. The cytotoxicity of saponins correlates with their cellular internalization. ChemMedChem. 2 (2007) 288-291

7. F. Li, P. P. Fernandez, P. Rajendran, K. M. Hui, G. Sethi, Diosgenin, a steroidal saponin, inhibits STAT3 signaling pathway leading to suppression of proliferation and chemosensitization of human hepatocellular carcinoma cells. Cancer Letters 292 (2010) 197-207.

8. S. J. Deng, B. Yu, Y. Z. Hui, H. Yu, X. Han, Synthesis of three diosgenyl saponins: dioscin, polyphyllin D, and balanitin 7. Carbohydr. Res. 317 (1999) 53-62.

9. B. Wang, J. Chun, Y. Liu, L. Han, Y. Wang, E. J, Y. S. Kim, M. Cheng, Synthesis of novel diosgenyl saponin analogues and apoptosisinducing activity on A549 human lung adenocarcinoma. Org. Biomol. Chem. 10 (2012) 8822-8834.

10. J. Chun, L. Han, M. Y. Xu, B. Wang, M. Cheng, Y. S. Kim. The induction of apoptosis by a newly synthesized diosgenyl saponin through the suppression of estrogen receptor-a in MCF-7 human breast 
cancer cells. Arch. Pharm. Res. 37 (2014) 1477-1486.

11. D. J. Newman, Natural products as leads to potential drugs: an old process or the new hope for drug discovery? J. Med. Chem., 51 (2008) 2589-2599.

12. J. Raju, R. Mehta, Cancer chemopreventive and therapeutic effects of diosgenin, a food saponin, Nutr. Cancer 61 (2009) 27-35.

13. W. G. Taylor, P. G. Fields, D. H. Sutherland, Insecticidal Components from Field Pea Extracts: Soyasaponins and Lysolecithins. J. Agric. Food Chem. 52 (2004) 7484-7490.

14. Y. Tian, G. Y. Gong, L. L. Ma, Z. Q. Wang, D. Song, M. Y. Fang, Anticancer effects of Polyphyllin I: An update in 5 years. Chem-Bio. Interact. 316 (2019) 108936-108943.

15. M. J. Kaskiw, M. L. Tassotto, J. Th'ng, Z, Jiang, Synthesis and cytotoxic activity of diosgenyl saponin analogues. Bioorgan. Med Chem. 16 (2008) 3209-3217.

16. J. Raju, R. Mehta, Cancer chemopreventive and therapeutic effects of diosgenin, a food saponin. Nutr. Cancer. 61 (2009) 27-35.

17. H. Yu, B. Yu, X. Wu, Y. Hui X. Han, Synthesis of a group of diosgenyl saponins with combined use of glycosyl trichloroacetimidate and thioglycoside donors. J. Chem. Soc., Perkin Trans. 1 (2000) 1445-1453.

18. S. L. Man, P. P. Lv, J. X. Cui, F. R. Liu, L. Peng, L. Ma, C. X. Liu, W.Y. Gao, Paris saponin II-induced paraptosis-associated cell death increased the sensitivity of cisplatin. Toxicol. Appl. Pharm. 406 (2020) 115206.

19. J. X. Cui, S. L. Man, N. N. Cui, L. Yang, Q. B. Guo, L. Ma, W. Y. Gao The synergistic anticancer effect of Formosanin C and Polyphyllin VII based on caspase-mediated cleavage of Beclin1 inhibiting autophagy and promoting apoptosis. Cell Proliferat. 52 (2019) e12520.

20. L. L. Yan, Y. J. Zhang, W. Y. Gao, S. L. Man, Y. Wang. In vitro and in vivo anticancer activity of steroid saponins of Paris polyphylla var yunnanensis. Exp. Onco. 31 (2009) 27-32.

21. S. L. Verstraeten, M. Albert, A. Paquot, G.G. Muccioli, D. Tyteca, M.P. Mingeot-Leclercq, Membrane cholesterol delays cellular apoptosis induced by ginsenoside Rh2, a steroid saponin. Toxicol. Appl. Pharmacol. 352 (2018) 59-67.

22. Z. Yang, E. L.-M. Wong, T. Y.-T. Shum, C.-M. Che, Y. Hui, Fluorophore-Appended Steroidal Saponin (Dioscin and Polyphyllin D) Derivatives. Org. Lett. 7 (2005) 669-672

23. H. Miyashita, T. Ikeda, T. Nohara. Synthesis of neosaponins and neoglycolipids containing a chacotriosyl moiety. Carbohydr. Res., 342 (2007) 2182-2191.

24. C. Li, B. Yu \& Y. Hui. Chemical Synthesis of Several 2'-O-, 3'-O-
Glycosylated Diosgenyl $\beta$-D-Glucopyranosides. J. Carbohyd. Chem. 18 (1999) 1107-1120.

25. B. Wang, J. Chun, Y. Liu, L. Han, Y. S. Wang, E. J. Joo, Y. S. Kim, M. S. Cheng. Synthesis of novel diosgenyl saponin analogues and apoptosis-inducing activity on A549 human lung adenocarcinoma. Org. Biomol. Chem. 10 (2012) 8822-8834

26. B. Li, B. Yu, Y. Hui, M. Li, X. Han, K.-P. Fung, An improved synthesis of the saponin, polyphyllin D. Carbohydr. Res. 331 (2001) 17.

27. R. R. Schmidt, J. Michael. Facile synthesis of- $\alpha$ and $\beta-O-g l y c o s y l$ imidates: Preparation of glycosides and disaccharides. Angew. Chem. Int. Ed. Engl. 19 (1980) 731-732.

28. H. Yu, X. W. Han, X. M. Liu, B. Yu, Y. Z. Hui and X. Bao. NMR studies on synthesized diosgenyl saponin analogs. Magn. Reson. Chem. 38 (2000) 704-706.

29. Y. Wang, Y. Zhang, Z. Zhu, S. Zhu, Y. Li, M. Li, B. Yu. Exploration of the correlation between the structure, hemolytic activity, and cytotoxicity of steroid saponins. Bioorg. Med. Chem. 15 (2007) 25282532.

30. M. S. Cheng, Q. L. Wang, Q. Tian, H. Y. Song, Y. X. Liu, Q. Li, Z. Yang. Total Synthesis of Methyl Protodioscin: A Potent Agent with Antitumor Activity. J. Org. Chem., 68 (2003) 3658-3662.

31. J. M. V Hernández-Vázquez, H. López-Muñoz, M. L. Escobar-Sánchez, F. Flores-Guzmán, B. Weiss-Steider, J. C. Hilario-Martínez, J. Sandoval-Ramírez, M. A. Fernández-Herrera, L. Sánchez Sánchez. Apoptotic, necrotic, and antiproliferative activity of diosgenin and diosgenin glycosides on cervical cancer cells. Eur. J. Pharmacol. 871 (2020) 172942

32. E. Al Sawah, D. C. Marchion, Y. Xiong, I. J. Ramirez, F. Abbasi, B. M. Boac, S. H. Bush, N. Bou Zgheib, E. C. McClung, B. R. Khulpateea, A Berry, A. Hakam, R. M. Wenham, J. M. Lancaster, P. L. Judson. The Chinese herb polyphyllin D sensitizes ovarian cancer cells to cisplatininduced growth arrest. J. Cancer Res. Clin. Oncol. 141 (2015) 237-242.

33. J. Chun, L. Han, M. Y. Xu, B. Wang, M. S. Cheng, Y. S. Kim. The induction of apoptosis by a newly synthesized diosgenyl saponin through the suppression of estrogen receptor- $\alpha$ in MCF-7 human breast cancer cells. Arch. Pharm. Res. 37 (2014) 1477-1486.

\section{Click here to remove instruction text...}

